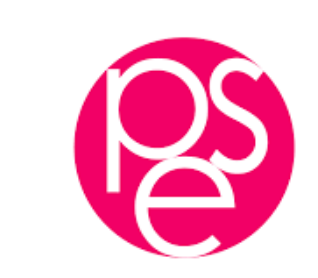

PARISSCHOOL OFECONOMICS
ECOLE D'ECONOMIE DE PARIS

WORKING PAPER Nº $2017-25$

Can we Identify the Fed's Preferences?

Jean-Bernard Chatelain

Kirsten Ralf

JEL Codes: C61, C62, E31, E52, E58

Keywords: Ramsey optimal policy, zero-credibility policy, Identification, Central bank preferences, New-Keynesian Phillips curve, Working capital channel
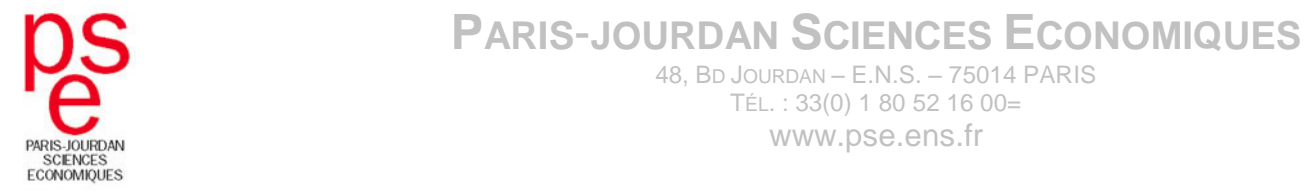


\title{
Can we Identify the Fed's Preferences?*
}

\author{
Jean-Bernard Chatelain ${ }^{\dagger}$ Kirsten Ralf ${ }^{\ddagger}$
}

December 2, 2017

\begin{abstract}
Using US data, we estimate optimal policy with a probability below one that the Fed reneges on its commitment ("limited credibility") versus discretionary policy where the Fed reneges on its commitment at all periods with a probability equal to one ("zero credibility"). The transmission mechanism is the new-Keynesian Phillips curve with auto-correlated cost-push shock. It includes the labor cost channel or the working capital channel. Discretion with zero credibility of the Fed is rejected. The working capital channel fits the data before Volcker's mandate. The labor cost channel fits the data since Volcker's mandate.
\end{abstract}

JEL classification numbers: C61, C62, E31, E52, E58.

Keywords: Ramsey optimal policy, zero-credibility policy, Identification, Central bank preferences, New-Keynesian Phillips curve,

Working capital channel.

\section{Introduction}

Can we test if the Fed follows Ramsey optimal policy under the limited credibility of quasi-commitment with a non-zero probability to commit (Debortoli and Nunes (2014), Schaumburg and Tambalotti (2007), Roberts (1987)) versus the Fed follows a policy with a complete lack of credibility with a zero probability to commit (Oudiz and Sachs (1985))? Are the Fed's preferences facing the same identification problem as Taylor rule parameters for both types of policies? Cochrane (2011) found that the simple Taylor rule parameters are not identified in new-Keynesian models including forward-looking inflation, but only the auto-correlation parameters of non-observable shocks.

Beginning with Simon (1956) certainty equivalence property of the linear quadratic regulator, the quadratic loss function describing policy-maker's preferences is used for modelling stabilization policy (Duarte (2009)). It took more than two decades for the estimation of Fed's preferences to begin with Salemi (1995), using inverse control (Salemi (2010)). Salemi (1995) took into account two structural breaks (1970-1, 1979-10) for three monetary policy regime during the period 1947-1992 using monthly data. Salemi (1995) includes a careful investigation of identification issues when the monetary policy transmission mechanism is a backward-looking vector auto-regressive (VAR) model. These

\footnotetext{
*We thank our discussants in conferences Robert Kollman, Sumudu Kankanamge, Gregory Levieuge and Efrem Castelnuovo, as well as Georges Overton for very helpful insights.

$\dagger$ Paris School of Economics, Université Paris 1 Pantheon Sorbonne, PjSE, 48 Boulevard Jourdan, 75014 Paris. Email: jean-bernard.chatelain@univ-paris1.fr

${ }^{\ddagger}$ ESCE International Business School, 10 rue Sextius Michel, 75015 Paris, Email: Kirsten.Ralf@esce.fr.
} 
identification issues are the same for Ramsey optimal policy under quasi-commitment (Debortoli and Nunes (2014)) with forward-looking variables, besides the optimal initial jump anchoring forward-looking variables (Ljungqvist and Sargent (2012)).

Following Salemi (1995), there are more than twenty papers estimating Fed's preferences since the 1960's with a structural break since the 1980's (Volcker-Greenspan period) assuming inflation is a predetermined variable or a forward-looking variable, assuming the acceleration Phillips curve or new-Keynesian Phillips curve as a monetary policy transmission mechanism: e.g. Cechetti and Ehrmann (2002), Ozlale (2003), Favero and Rovelli (2003), Castelnuovo and Surico (2004), Castelnuovo (2006), Soderstrom et al. (2005), Juillard et al. (2006), Salemi (2006), Kara (2007), Adjemian and Devulder (2011), Adolfson et al. (2011), Ilbas (2012), Levieuge and Lucotte (2014), Paez-Farrell (2015), Debortoli and Lakdawala (2016) and many others.

Ramsey optimal policy including the probability to re-optimize each period is mentioned "stochastic replanning" (Roberds (1987)), "quasi commitment" (Schaumburg and Tambalotti (2007), Kara (2007)) or "loose commitment" (Debortoli and Nunes (2010)). This assumption is observationally equivalent to Chari and Kehoe (1990) optimal policy under sustainable plans facing a punishment threat at a given horizon $T$ in case of deviation of an Ramsey optimal policy plan (Fujiwara, Kam, Sunakawa (2016)).

We estimate Debortoli and Nunes (2014) and Schaumburg and Tambalotti (2007) quasi commitment model, where the transmission mechanism is the new-Keynesian Phillips curve with an auto-regressive cost-push shock. These empirical results can be compared to estimations of the new-Keynesian Phillips curve (Mavroeidis et al. (2014)). We avoid the Lucas' critique taking into account the endogeneity of the policy instruments due to a feedback policy rule. We also estimate that case of the working capital channel with interest smoothing in the Fed's loss function. In this case, the model fits data as well as a non-structural VAR for the pre-Volcker period. We test Ramsey versus zero-credibility policy. Assuming the minimal number of lags for the transmission mechanism, this paper makes progress in these five directions:

(1) We disclose the estimates of the reduced form stable eigenvalues of the estimated VAR for Ramsey versus zero-credibility and check Blanchard and Kahn (1980) determinacy condition. The estimations should not correspond to the same number of stable eigenvalues for both models. Söderlind (1999) algorithm provides no hints on checking the number of stable eigenvalues for Ramsey versus zero-credibility policy.

(2) We disclose the conditions for the exact identification of parameters for each model.

(3) We test the signs restrictions of reduced form policy rule parameters.

(4) We test the misspecification of each models, using for example Durbin (1970) test.

(5) We compare both estimations with the estimations of a non-structural vector auto-regressive model.

Section 2 presents our estimation methods of Ramsey optimal policy and zero-credibility policy. Section 3 details specification tests of zero-credibility versus Ramsey optimal policy. Section 4 presents estimations on US data during 1960-2006 for a labor cost channel and section 5 for a cost of working capital channel. The last section concludes. 


\section{Ramsey versus Zero-credibility Monetary Policy}

\subsection{Monetary Policy Transmission Mechanism Including or not the Cost of Working Capital}

The reference new-Keynesian Phillips curve is the monetary policy transmission mechanism:

$$
\pi_{t}=\beta E_{t}\left[\pi_{t+1}\right]+\kappa x_{t}+u_{t} \text { where } \kappa>0,0<\beta<1
$$

where $x_{t}$ represents the welfare-relevant output gap, i.e. the deviation between $(\log )$ output and its efficient level. $\pi_{t}$ denotes the rate of inflation between periods $t-1$ and $t$. $u_{t}$ denotes a cost-push shock. $\beta$ denotes the discount factor. $E_{t}$ denotes the expectation operator. The cost push shock $u_{t}$ includes an exogenous auto-regressive component:

$$
u_{t}=\rho u_{t-1}+\varepsilon_{u, t} \text { where } 0<\rho<1 \text { and } \varepsilon_{u, t} \text { i.i.d. normal } N\left(0, \sigma_{u}^{2}\right)
$$

where $\rho$ denotes the auto-correlation parameter and $\varepsilon_{t}$ is identically and independently distributed (i.i.d.) according to a normal distribution with constant variance $\sigma_{u}^{2}$.

The reduced-form parameter (denoted $\kappa$ ) of the slope of the new-Keynesian Phillips curve relates inflation to marginal cost or to the output gap. It depends on four structural parameters: the representative household discount factor $\beta$, the household's elasticity of substitution between each differentiated goods $\varepsilon$, the measure of decreasing returns to scale of labor in the production functions of the firms $\eta$, and the proportion of firms who do not reset their price each period $\theta$ (Gali (2015), chapter 3):

$$
\kappa(\beta, \varepsilon, \eta, \theta)=\frac{(1-\theta)(1-\beta \theta)}{\theta} \frac{(1-\eta)}{(1-\eta+\eta \varepsilon)} .
$$

In the new-Keynesian model, labor is assumed to be the only input in the production function. The cost of capital channel of monetary policy is ruled out by assumption. Christiano, Trabandt and Walentin (2010) assume that labor cost is financed by working capital. The marginal cost in the new-Keynesian Phillips curve is then a linear combination of labor and capital cost (Christiano, Trabandt and Walentin (2010), equation $35)$ :

$$
\gamma(1+\phi) x_{t}+\frac{\psi}{(1-\psi) \beta+\psi} i_{t}
$$

We estimate two polar cases. When material inputs are not used in production $(\gamma=1)$ and when no labor cost is financed by working capital $(\psi=0)$, the cost of labor is the only cost taken into account and the output gap is the policy instrument. When material inputs are all used in production $(\gamma=0)$ and when all labor cost is financed by working capital $(\psi=1)$, the cost of capital is the only cost taken into account with a slope of the new-Keynesian Phillips curve denoted $\kappa_{i}$. Then, the Federal funds rate is the policy instrument with an interest smoothing parameter $\alpha_{i}$ for the Fed's preferences.

\subsection{Monetary Policy Regimes and Central Bank Behavior}

In a monetary policy regime indexed by $j$, a policy maker has a period loss function $\frac{1}{2}\left(\pi_{t}^{2}+\alpha_{x, j} x_{t}^{2}\right)$ for the labor cost model or the period loss function includes an interest 
smoothing term $\frac{1}{2}\left(\pi_{t}^{2}+\alpha_{i, j} i_{t}^{2}\right)$ for the cost of working capital model. Fed's preferences are represented by the relative cost $\alpha_{x, j}>0$ or $\alpha_{i, j}>0$ of changing its policy instrument. A policy maker may re-optimize on each future period with exogenous probability $1-q$ strictly below one ("stochastic replanning" (Roberds, 1987), "quasi commitment" (Schaumburg and Tambalotti, 2007; Kara 2007) or "loose commitment" (Debortoli and Nunes, 2014)).

Following Schaumburg and Tambalotti (2007), we assume that the mandate to minimize the loss function is delegated to a sequence of policy makers with a commitment of random duration. The degree of credibility is modelled as if it is a change of policy-maker with a given probability of reneging commitment and re-optimizing optimal plans. The length of their tenure or "regime" depends on a sequence of exogenous i.i.d. Bernoulli signals $\left\{\eta_{t}\right\}_{t>0}$ with $E_{t}\left[\eta_{t}\right]_{t>0}=1-q$, with $0<q<1$. If $\eta_{t}=1$, a new policy maker takes office at the beginning of time $t$. Otherwise, the incumbent stays on. A higher probability $q$ can be interpreted as a higher credibility. As seen below, this leads to use a "credibility adjusted" discount factor $\beta q$ in the policy maker's optimal behavior.

Secondly, in this new monetary policy regime indexed by $k$, there may be a switch of the transmission mechanism parameter (the slope of the Phillips curve) $\kappa_{k}$ including in particular, a switch of the representative household's elasticity of substitution between each differentiated goods $\varepsilon_{k}$. Thirdly, the new policy maker may have new preferences $\alpha_{x, k}$. If the policy maker is maximizing welfare, its preferences are given by the new values of structural parameters of the transmission mechanism $\alpha_{x, k}=\frac{\kappa_{k}}{\varepsilon_{k}}$ (Gali (2015)). More generally, and stepping beyond the welfare-theoretic justification for (1), one can interpret $\alpha_{x}$ as the weight attached by the central bank to deviations of output from its efficient level (relative to price stability) in its own loss function, which does not necessarily have to coincide with the household's. Because structural parameters may change for a new regime $k$, long run equilibrium values may also change in the estimation.

Under regime $j$, policy plans solve the following problem (omitting subscript $j$ for the central bank preferences $\alpha_{x}$, transmission mechanism parameter $\kappa$, the auto-correlation of the cost-push shock $\rho$ and its variance of its disturbances $\varepsilon_{t}$ ):

$$
\begin{aligned}
V^{j k}\left(u_{0}\right) & =-E_{0} \sum_{t=0}^{t=+\infty}(\beta q)^{t}\left[\frac{1}{2}\left(\pi_{t}^{2}+\alpha_{x} x_{t}^{2}\right)+\beta(1-q) V^{j k}\left(u_{t}\right)\right] \\
\text { s.t. } \pi_{t} & \left.=\kappa x_{t}+\beta q E_{t} \pi_{t+1}+\beta(1-q) E_{t} \pi_{t+1}^{k}+u_{t} \text { (Lagrange multiplier } \gamma_{t+1}\right) \\
u_{t} & =\rho u_{t-1}+\varepsilon_{t}, \forall t \in \mathbb{N}, u_{0} \text { given. }
\end{aligned}
$$

The utility the central bank obtains is next period objectives change is denoted $V^{j k}$. Since when objectives change, the central bank loses its commitment, this value function depends on the policies of the alternative regime. Inflation expectations are an average between two terms. The first term, with weight $q$ is the inflation that would prevail under the current regime upon which there is commitment. The second term with weight $1-q$ is the inflation that would be implemented under the alternative regime, which is taken as given by the current central bank. The key change is that the narrow range of values for the discount factor $\beta \in[0.99,1]$ for quarterly data (4\% discount rate at most) is much wider for the "credibility weighted discount factor" of the policy maker: $\beta q \in] 0,1]$. In what follows, the notation $\beta$ will correspond to $\beta q$, in order to simplify notations and because the theoretical model does not allow to identify separately $\beta$ and 
$q$ for the estimation.

\subsection{VAR Representation of Ramsey optimal policy}

Differentiating the Lagrangian with respect to the policy instrument (output gap $x_{t}$ ) and to the policy target (inflation $\pi_{t}$ ) yields the first order conditions (see appendix 2):

$$
\left\{\begin{array} { c } 
{ \frac { \partial \mathcal { L } } { \partial \pi _ { t } } = 0 : \pi _ { t } + \gamma _ { t + 1 } - \gamma _ { t } = 0 } \\
{ \frac { \partial \mathcal { L } } { \partial x _ { t } } = 0 : \alpha _ { x } x _ { t } - \kappa \gamma _ { t + 1 } = 0 }
\end{array} \Rightarrow \left\{\begin{array}{c}
x_{t}=x_{t-1}-\frac{\kappa}{\alpha_{x}} \pi_{t} \\
x_{t}=\frac{\kappa}{\alpha_{x}} \gamma_{t+1}=\frac{\kappa}{\alpha_{x}}\left(\gamma_{t}-\pi_{t}\right)
\end{array}\right.\right.
$$

that must hold for $t=1,2, \ldots$ The central bank's Euler equation $\left(\frac{\partial \mathcal{L}}{\partial \pi_{t}}=0\right)$ links recursively the future or current value of central bank's policy instrument $x_{t}$ to its current or past value $x_{t-1}$, because of the central bank's relative cost of changing her policy instrument is strictly positive $\alpha_{x}>0$. This non-stationary Euler equation adds an unstable eigenvalue in the central bank's Hamiltonian system including three laws of motion of one forward variable (inflation $\pi_{t}$ ) and of two predetermined variables $\left(u_{t}, x_{t}\right)$ or $\left(u_{t}, \gamma_{t}\right)$.

The natural boundary condition $\gamma_{0}=0$ minimizes the loss function with respect to inflation at the initial date:

$$
\gamma_{0}=0 \Rightarrow x_{-1}=-\frac{\kappa}{\alpha_{x}} \gamma_{0}=0 \text { and } \pi_{0}=-\frac{\alpha_{x}}{\kappa} x_{0} \neq 0
$$

It predetermines the policy instrument which allows to anchor the forward-looking policy target (inflation). The inflation Euler equation corresponding to period 0 is not an effective constraint for the central bank choosing its optimal plan in period 0 . The former commitment to the value of the policy instrument of the previous period $x_{-1}$ is not an effective constraint. The policy instrument is predetermined at the value zero $x_{-1}=0$ at the period preceding the commitment. Combining the two first order conditions to eliminate the Lagrange multipliers yields the optimal initial anchor of forward inflation $\pi_{0}$ on the predetermined policy instrument $x_{0}$.

Ljungqvist and Sargent (2012, chapter 19) seek the stationary equilibrium process using the augmented discounted linear quadratic regulator solution of the Hamiltonian system (Anderson, Hansen, McGrattan and Sargent (1996)) as an intermediate step (Chatelain and Ralf (2017) algorithm). The policy instrument is exactly correlated with private sectors variables:

$$
x_{t}=F_{\pi} \pi_{t}+F_{u} u_{t} .
$$

We estimate three observationally equivalent estimations of Ramsey optimal policy structural VAR of the two observable variables (inflation and the policy instrument), using feasible generalized non-linear least squares for a system of equations (see appendix 2).

The first estimation estimates the two stable eigenvalues: the exogenous autocorrelation of cost-push shock $\rho$, the reduced form eigenvalue $\lambda$ and the reduced from policy rule parameter with respect to inflation $F_{\pi}$ :

$$
\left(\begin{array}{c}
\pi_{t+1} \\
x_{t+1}
\end{array}\right)=\left(\begin{array}{cc}
\rho \lambda & (1-\rho) \lambda \frac{1}{F_{\pi}} \\
\rho(\lambda-1) F_{\pi} & \rho+\lambda-\rho \lambda
\end{array}\right)\left(\begin{array}{c}
\pi_{t} \\
x_{t}
\end{array}\right)+\left(\begin{array}{c}
\eta_{t+1} \\
\frac{\beta \lambda \rho-1}{F_{\pi}} \varepsilon_{t+1}
\end{array}\right)
$$

The auto-correlation coefficient $\rho$ is into the matrix of the VAR of inflation and the 
policy instrument. It does not appear into the disturbances, which are now white noise, a necessary condition for estimating a VAR. We assume an i.i.d. measurement error $\eta_{t+1}$ in order to avoid the stochastic singularity of the perfect collinearity of the inflation equation predicted by the Ramsey optimal policy theory (appendix 2). A high $R^{2}$ for the inflation equation would signal that the variance of this measurement error is sufficiently small to remain close to the theoretical model.

$$
\left(\begin{array}{c}
\pi_{t+1} \\
x_{t+1}
\end{array}\right)=\left(\begin{array}{cc}
\rho \frac{1-\kappa F_{\pi}}{\beta} & (1-\rho) \frac{1-\kappa F_{\pi}}{\beta} \frac{1}{F_{\pi}} \\
\rho\left(\frac{1-\kappa F_{\pi}}{\beta}-1\right) F_{\pi} & \rho+\frac{1-\kappa F_{\pi}}{\beta}-\rho \frac{1-\kappa F_{\pi}}{\beta}
\end{array}\right)\left(\begin{array}{c}
\pi_{t} \\
x_{t}
\end{array}\right)+\left(\begin{array}{c}
\eta_{t+1} \\
\frac{\beta \lambda \rho-1}{F_{\pi}} \varepsilon_{t+1}
\end{array}\right)
$$

The second estimation estimates the two stable eigenvalues: the exogenous $\rho$, the reduced form eigenvalue $\lambda$ and the ratio of two structural parameters $\frac{\alpha_{x}}{\kappa}=\frac{1}{\varepsilon}$ where $\varepsilon$ is the household's elasticity of substitution between each differentiated goods, if the central bank maximizes the representative household welfare.

$$
\left(\begin{array}{c}
\pi_{t+1} \\
x_{t+1}
\end{array}\right)=\left(\begin{array}{cc}
\rho \lambda & (1-\rho)(1-\lambda) \frac{\alpha_{x}}{\kappa} \\
-\rho \lambda \frac{\kappa}{\alpha_{x}} & \rho+\lambda-\rho \lambda
\end{array}\right)\left(\begin{array}{c}
\pi_{t+1} \\
x_{t+1}
\end{array}\right)+\left(\begin{array}{c}
\eta_{t+1} \\
\frac{\beta \lambda \rho-1}{F_{\pi}} \varepsilon_{t+1}
\end{array}\right)
$$

The third estimation substitutes the reduced form stable eigenvalue $\lambda$ by its nonlinear function of the three structural parameters $\beta, \alpha_{x}, \kappa$ in the above VAR of the second estimation.

$$
\lambda=\frac{1-\kappa F_{\pi}}{\beta}=\frac{1}{2}\left(1+\frac{1}{\beta}+\frac{\kappa^{2}}{\beta \alpha_{x}}\right)-\sqrt{\frac{1}{4}\left(1+\frac{1}{\beta} \frac{\kappa^{2}}{\beta \alpha_{x}}\right)^{2}-\frac{1}{\beta q}}=\delta
$$

This requires an identification restriction that we set on the discount factor $\beta$. We estimate separately three structural parameters: the auto-correlation of the cost-push shock $\rho$, the preference of the Fed $\alpha_{x}$, and the slope of the new-Keynesian Phillips curve $\kappa$. Only three structural parameters can be identified: $\rho, \lambda, F_{\pi}$ or $\rho, \lambda, \frac{\alpha_{x}}{\kappa}$ or $\rho, \alpha(\beta q), \kappa(\beta q)$ for a given value of the discount factor $\beta q$ (see appendix 2):

$$
\kappa(\beta)=\frac{1-\lambda \beta q}{F_{\pi}} \Rightarrow \alpha_{x}(\beta)=\left(\frac{\lambda}{1-\lambda}\right) \frac{1}{F_{\pi}} \kappa(\beta q) .
$$

If initial values of inflation and of the policy instrument (in deviation from their equilibrium values) were perfectly measured at the date of commitment, the ratio $\frac{\alpha_{x}}{\kappa}$ would be over-identified by the optimal initial anchor of forward inflation on the predetermined policy instrument equation:

$$
\frac{\alpha_{x}}{\kappa}=\frac{-\pi_{0}}{x_{0}} .
$$

The semi-reduced form cost-push shock rule parameter $F_{u}$ requires an identification restriction, for example, setting a value for $\beta$ (see appendix 2):

$$
F_{u}(\beta)=\frac{-1}{1-\beta \rho \lambda} F_{\pi}<0 .
$$

The standard error $\sigma_{u}$ of cost-push shock is computed using the standard error of residuals $\sigma_{\varepsilon, x}$ of the output gap rule equation in the $\operatorname{VAR}(1)$. It requires an identification 
restriction, because it depends on $F_{u}$ :

$$
\sigma_{u}(\beta)=\frac{\sigma_{\varepsilon, x}}{F_{u}(\beta)}=\frac{\beta \rho \lambda-1}{F_{\pi}} \sigma_{\varepsilon, x} .
$$

The standard error of the measurement of the inflation equation $\sigma_{\pi}$ (which is theoretically predicted to be zero) and its covariance with the cost push shock $\sigma_{x \pi}=F_{u} \sigma_{x u}$ are also available.

One identifying equation is missing in order to identify the remaining four structural parameters $\left(\alpha_{x}, \kappa, \beta, \sigma_{u}\right)$ and the negative feedback rule parameter $F_{u}$. We set an identification restriction on the credibility weighted discount factor to a given values in the estimations.

For each regime, we estimate the slope of the Phillips curve $\kappa_{j}$, the elasticity of substitution between each differentiated goods $\left(\frac{1}{\varepsilon_{j}}=\frac{\alpha_{x, j}}{\kappa_{j}}\right)$, the Fed's preferences $\alpha_{x, j}$, the auto-correlation of the cost-push shock $\rho_{j}$ and its variance $\sigma_{u, j}^{2}$. We calibrate the two parameters $\beta q$. The measure of decreasing returns to scale of labor in the production functions of the firms $\eta$ and the proportion of firms who do not reset their price each period $\theta$ face an under-identification problem detailed in the next section.

\subsection{Infinite Horizon Zero-Credibility Policy}

With quasi-commitment, the probability of not reneging commitment could be infinitely small (near-zero credibility), but it remains strictly positive: for example, $q=10^{-7}>0$ (Roberts (1987)) with $q \in] 0,1]$. Before Roberts (1987) stochastic replanning article, Oudiz and Sachs (1985) invented an infinite horizon zero-credibility policy, which holds when the policy maker re-optimizes with certainty for all future periods. This forever complete lack of credibility corresponds to $q=0$. This zero-credibility policy is mentioned as "discretion" by Gali (2015) with a very minor change with respect to Oudiz and Sachs (1985) detailed in the appendix. Testing Roberts (1987) against Oudiz and Sachs (1985) amounts to test the assumption of a non-zero probability of not replanning and reneging commitment $q \in] 0,1]$ against a zero probability of not reneging commitment $q=0$ for ever, so that Oudiz and Sachs (1985) equilibrium is unlikely.

The central bank minimizes its loss function subject to the new-Keynesian Phillips curve and such that private sector and the central bank policy instrument reacts only to the contemporary predetermined variable $u_{t}$ at all periods $t$ with a perfect correlation. These zero-credibility rules are determined by time-invariant rule parameters $N_{Z C}$ and $F_{u, Z C}$ (indexed by $Z C$ ) which are optimally chosen for all periods:

$$
\pi_{t}=N_{Z C} u_{t} \text { and } x_{t}=F_{u, Z C} u_{t} \Rightarrow x_{t}=F_{\pi, Z C} \pi_{t} \text { with } F_{\pi, Z C}=\frac{F_{u, Z C}}{N_{Z C}}
$$

The subscript TC is for zero-credibility policy. The central bank zero-credibility rule responds only to inflation with a perfect correlation. Substituting the private sector's inflation rule and the policy rule in the loss function:

$$
\max _{\left\{\pi, x_{t}\right\}}-\frac{1}{2} E_{0} \sum_{t=0}^{+\infty} \beta^{t}\left(\pi_{t}^{2}+\alpha_{x} x_{t}^{2}\right)=\underset{\left\{F_{u, Z C}, N_{Z C}\right\}}{\max }-\frac{1}{2}\left(N_{Z C}^{2}+\alpha_{x} F_{u, Z C}^{2}\right) \frac{u_{0}^{2}}{1-\beta \rho^{2}}
$$

The central bank first order condition is: 


$$
\begin{array}{r}
0=N_{u, Z C} \frac{\partial N_{u, Z C}}{\partial F_{u, Z C}}+\alpha_{x} F_{u, Z C} \\
F_{\pi, Z C}=\frac{F_{u, Z C}}{N_{Z C}}=-\frac{1}{\alpha_{x}} \frac{\partial N_{u, Z C}}{\partial F_{u, Z C}}
\end{array}
$$

Substituting the private sector's inflation rule and the policy rule in the inflation law of motion leads to the following relation between $N_{Z C}$ on date $t, N_{Z C, t+1}$ and $F_{u, Z C}$ :

$$
\begin{aligned}
\pi_{t} & =\beta E_{t}\left[\pi_{t+1}\right]+\kappa x_{t}+u_{t} \Rightarrow \\
N_{Z C} u_{t} & =\beta N_{Z C, t+1} \rho u_{t}+\kappa F_{u, Z C} u_{t}+u_{t} \\
N_{Z C} & =\beta \rho N_{Z C, t+1}+\kappa F_{u, Z C}+1
\end{aligned}
$$

The central bank foresees that $N_{Z C, t+1}=N_{Z C}$ in its optimization (Oudiz and Sachs' (1985), appendix):

$$
N_{Z C}=\frac{\kappa F_{u, Z C}+1}{1-\beta \rho}=\frac{\kappa F_{\pi, Z C} N_{Z C}+1}{1-\beta \rho} \Rightarrow \frac{\partial N_{u, Z C}}{\partial F_{u, Z C}}=\frac{\kappa}{1-\beta \rho}
$$

The endogenous rule parameters are increasing function of the central bank cost of changing the policy instrument $\alpha_{x}$. They are bounded by limit values of $\left.\alpha_{x} \in\right] 0,+\infty[$ :

$$
\begin{aligned}
0 & <\frac{\pi_{t, Z C}}{u_{t}}=N_{Z C}\left(\alpha_{x}\right)=\frac{\alpha_{x}(1-\beta \rho)}{\alpha_{x}(1-\beta \rho)^{2}+\kappa^{2}}<N=\frac{1}{1-\beta \rho} \\
-\frac{1}{\kappa}<\frac{x_{t, Z C}}{u_{t}}=F_{u, Z C}\left(\alpha_{x}\right) & =\frac{-\kappa}{\alpha_{x}(1-\beta \rho)^{2}+\kappa^{2}}<0 \\
-\infty & <\frac{x_{t, Z C}}{\pi_{t, Z C}}=F_{\pi, Z C}\left(\alpha_{x}\right)=\frac{F_{u, Z C}}{N_{Z C}}=\frac{-\kappa}{\alpha_{x}(1-\beta \rho)}<\frac{-\kappa}{\alpha_{x}}<0
\end{aligned}
$$

The policy instrument (the output gap) is exactly negatively correlated $\left(F_{\pi, Z C}<0\right)$ with the policy target, inflation.

\section{Specification tests of Ramsey versus Zero-Credibility Policy}

\subsection{Sign restrictions of reduced form rule parameters}

Oudiz and Sachs (1985) equilibrium implies a bifurcation (a sharp qualitative change) of the economy dynamic system with respect to the later paper of Roberts (1987) stochastic replanning equilibrium.

Proposition 1. Opposite sign restrictions. The inflation policy rule parameter $F_{\pi}$ is positive and bounded using Roberts (1987) stochastic replanning equilibrium. The inflation policy rule $F_{\pi, Z C}$ is negative and unbounded using Oudiz and Sachs (1985) zerocredibility equilibrium. There is a saddle-node bifurcation on the inflation eigenvalue $0<$ $\lambda<1<\lambda_{Z C}$ when shifting from negative-feedback of Ramsey optimal policy under quasi- 
commitment equilibrium (eigenvalue $\lambda$ ) to the positive-feedback mechanism of infinite horizon zero-credibility equilibrium (eigenvalue $\lambda_{Z C}$ ).

Proof: The reduced form inflation rule parameters $F_{\pi, Z C}$ of zero-credibility policy (respectively $F_{\pi}$ of Ramsey optimal policy) is an affine negative function of the inflation eigenvalue $\lambda_{Z C}$ (respectively $\lambda$ ). The inflation rule parameters satisfies the following inequalities:

$$
F_{\pi, Z C}=-\frac{1}{1-\beta \rho} \frac{\kappa}{\alpha_{x}}<0<\frac{1-\beta}{\kappa}<F_{\pi}=\frac{1-\beta \lambda}{\kappa}<\frac{1}{\kappa}
$$

The inflation eigenvalues satisfies the following inequalities:

$$
\begin{aligned}
& 0<\lambda=\frac{1}{2}\left(1+\frac{1}{\beta}+\frac{\kappa^{2}}{\beta \alpha_{x}}\right)-\sqrt{\frac{1}{4}\left(1+\frac{1}{\beta}+\frac{\kappa^{2}}{\beta \alpha_{x}}\right)^{2}-\frac{1}{\beta}}<1 \\
& 1 \leq \frac{1}{\beta}<\lambda_{Z C}=\frac{1-\kappa F_{\pi, Z C}}{\beta}=\frac{1}{\beta}+\frac{1}{\beta} \frac{1}{1-\beta \rho} \frac{\kappa^{2}}{\alpha_{x}}
\end{aligned}
$$

The policy instrument (or the Lagrange multiplier on forward-looking inflation) is optimally predetermined for Ramsey optimal policy whereas it is forward-looking with infinite horizon zero-credibility policy. This implies an additional stable eigenvalue for Ramsey optimal policy with respect to zero-credibility policy, according to Blanchard and Kahn (1980) determinacy condition. QED.

Figures 1 and 2: Inflation rule parameter and inflation eigenvalues functions of $\alpha_{x}$ for Ramsey optimal policy (solid line) and zero-credibility policy (dash line) for $\rho=0.995$, $\kappa=0.340, \beta=0.99$.
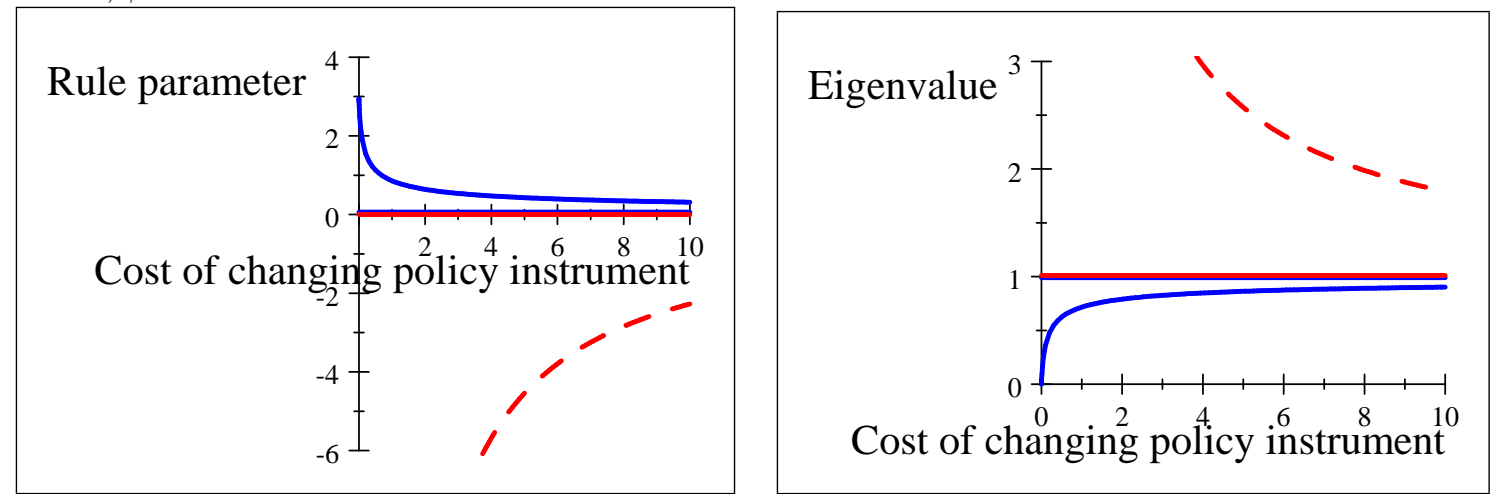

The estimated parameters $\rho=0.995, \kappa=0.340$ for a given $\beta=0.99$ of the Ramsey optimal policy model are found during Volcker-Greenspan's Fed starting 1979q3-2006q2 in the next section. Figure 1 plots the positive-feedback inflation rule parameter $F_{\pi, Z C}<0$ of zero-credibility policy (dashed line) and respectively the negative-feedback inflation rule parameter $F_{\pi}>0$ of Ramsey optimal policy (continuous line) as non-linear increasing (respectively decreasing) function of the relative cost of changing the policy instrument $\alpha_{x}$. The estimated parameters correspond to the point: $\alpha_{x}=4.552$ and $F_{\pi}=0.447$. Figure 2 plots the related eigenvalue $\lambda_{Z C}$ of zero-credibility policy (and respectively the eigenvalue $\lambda$ of Ramsey optimal policy) as non-linear decreasing (respectively increasing) function of the relative cost of changing the policy instrument $\alpha_{x}$. The estimated parameters correspond to the point $\alpha_{x}=4.552$ and $\lambda=0.856$.

For an infinite cost of changing the policy instrument $\left(\alpha_{x} \rightarrow+\infty\right.$, the Fed has maximal inertia): the negative-feedback rule parameter $F_{\pi}$ decreases to its lowest value (zero). The 
stable inflation eigenvalue $\lambda$ tends to one for Ramsey optimal policy. For zero-credibility policy, the positive-feedback rule parameter $F_{\pi}$ increases up to zero (with negative values). The unstable inflation eigenvalue $\lambda_{Z C}$ decreases towards to $1 / \beta>1$.

For a near-zero cost of changing the policy instrument $\left(\alpha_{x} \rightarrow 0\right.$, the Fed is an inflation nutter), the negative-feedback rule parameter $F_{\pi}$ increases to its largest bounded positive value. The stable inflation eigenvalue $\lambda$ tends to zero for Ramsey optimal policy. For zero-credibility policy, the positive-feedback rule parameter decreases to minus infinity (with negative values). The unstable inflation eigenvalue $\lambda_{Z C}$ tends to plus plus infinity.

\subsection{Specification tests of zero-credibility policy}

Time-consistent policy is described by a permanent anchor of inflation on the output gap and by two $\mathrm{AR}(1)$ processes of inflation and of the output gap. Variables, such as inflation $\left(\pi_{t}+\pi^{*}\right)$ are not computed as deviations of equilibrium (already denoted $\left.\pi_{t}\right)$. Estimates of equilibrium values $\left(\pi^{*}, x^{*}\right)$ are then sample mean values found in the estimates of intercepts. The reduced form zero-credibility policy policy rule to be tested (which corresponds to a permanent anchor of inflation on the output gap) allows to estimate the reduced form zero-credibility policy rule parameter $F_{\pi, Z C}$ :

$$
\begin{aligned}
x_{t}+x^{*} & =F_{\pi, Z C}\left(\pi_{t}+\pi^{*}\right)+\left(x^{*}-F_{\pi, Z C} \pi^{*}\right)+\varepsilon_{x \pi, t} \text { with } \\
\varepsilon_{x \pi, t} & =0 \text { for all dates, } R^{2}=1 \text { and } F_{\pi, Z C}<0
\end{aligned}
$$

We assume i.i.d. measurement errors $\eta_{t}$ for the inflation equation of Ramsey optimal policy. By the same token, for the infinite horizon zero-credibility policy, we also assume an i.i.d. measurement error $\varepsilon_{x \pi, t}$, for the policy rule equation, in order to avoid the stochastic singularity of the perfect negative correlation predicted by the theory. A high $R^{2}$ for the inflation equation would signal this measurement error to be sufficiently small and close to the theoretical model. For example, one can perform a one-sided test of a composite null hypothesis of a simple correlation very close to minus one: $H_{0, Z C, S S}$ : $r_{x \pi}<-0.99$. A first specification test of the negative sign restriction of zero-credibility policy is more informative.

Negative sign restriction (NSR): $H_{0, Z C, N S}: r_{x \pi}<0$

A positive sign of the zero-credibility rule suggests Ramsey optimal policy as an alternative, with an opposite sign on the policy rule parameter $F_{\pi}$. The simple correlation between the output gap and inflation provides another estimate of the zero-credibility policy rule parameter $F_{\pi, Z C}=r_{x \pi} \sigma_{\varepsilon, x} / \sigma_{\varepsilon, \pi}<0$. It is equal to the one found using the ratio of standard errors of residuals of the $\operatorname{AR}(1)$ estimations for inflation and for the output gap : $F_{\pi, Z C}=-\sigma_{\varepsilon, x} / \sigma_{\varepsilon, \pi}$ only if the following condition is satisfied: $r_{x \pi}=-1$ (stochastic singularity).

The rejection of stochastic singularity is expected to be stronger in the zero-credibility policy rule with a lower $R^{2}$ (because it does not include a lagged dependent variable) than the one of the Ramsey inflation equation (which includes lagged inflation). Hence, $a$ second specification test of zero-credibility policy versus Ramsey optimal policy is a Durbin (1970) test of the auto-correlation of residuals of these measurement errors of the zerocredibility positive-feedback policy rule. The measurement errors of the zero-credibility policy rule should not be auto-correlated according to the theory of zero-credibility policy: 
White noise disturbances: $H_{0, Z C, \text { Durbin }}: \rho_{\varepsilon, x \pi}=0$ for $\varepsilon_{x \pi, t}=\rho_{\varepsilon, x \pi} \varepsilon_{x \pi, t}+\eta_{t}$ with $\eta_{t}$ i.i.d.

If measurement errors are correlated, this alternative hypothesis suggests that at least one lagged policy instrument is missing in the regression of the policy rule. This is exactly a reduced form of the Ramsey optimal policy rule which also depends on inflation. Finally, we can perform another test. In the zero-credibility feedback rule, the policy instrument is a linear function of the policy target. The two $\mathrm{AR}(1)$ process for inflation and the output gap have common auto-correlation parameters:

$$
\begin{aligned}
& \pi_{t}+\pi^{*}=\rho\left(\pi_{t-1}+\pi^{*}\right)+(1-\rho) \pi^{*}+N_{Z C} \varepsilon_{u, t} \text { with } \varepsilon_{u, t} \text { i.i.d. } \\
& x_{t}+x^{*}=\rho\left(x_{t-1}+x^{*}\right)+(1-\rho) x^{*}+F_{\pi, Z C} N_{Z C} \varepsilon_{u, t} \text { with } \varepsilon_{u, t} \text { i.i.d. }
\end{aligned}
$$

We can test the hypothesis of a common auto-correlation parameter for the policy target (inflation) and for the policy instrument (output gap):

$$
\text { Common auto-correlation (CA): } H_{0, Z C, C A}: \rho_{\pi}=\rho_{x}
$$

Proposition 2: For zero-credibility policy, only the auto-correlation coefficient of the cost-push shock $\rho$ can be identified. But the four other structural parameters are not identified: the Fed's preferences parameter $\alpha_{x}$, the slope of the new-Keynesian Phillips curve $\kappa$, the discount factor $\beta$ and the variance of the cost-push shock $\sigma_{\varepsilon, u}^{2}$. If the Fed's preferences is a welfare loss function, where Fed's preferences parameter is endogenous $\left(\alpha_{x}=\frac{\kappa}{\varepsilon}\right)$, the representative household's elasticity of substitution between each differentiated goods $\varepsilon$ is not identified.

Proof. If common auto-correlation hypothesis is not rejected, the $\mathrm{AR}(1)$ estimates of the policy target and of the policy instrument identify the auto-correlation parameter of the non-observable cost-push shock: $\rho$. The ratio of the standard errors of residuals of each $\mathrm{AR}(1)$ estimations of inflation and output gap provides another estimate of the zero-credibility reduced form rule parameter $F_{\pi, Z C}$, (if $r_{x \pi}=1$ ), if the hypothesis of a negative sign is not rejected:

$$
F_{\pi, Z C}=-\sigma_{\varepsilon, x} / \sigma_{\varepsilon, \pi}
$$

The variance $\sigma_{\varepsilon, \pi}^{2}$ of perturbations of the inflation $\operatorname{AR}(1)$ process is:

$$
\sigma_{\varepsilon, \pi}^{2}=N_{Z C}^{2} \sigma_{\varepsilon, u}^{2} \Rightarrow N_{Z C}^{2}=\frac{\sigma_{\varepsilon, \pi}^{2}}{\sigma_{\varepsilon, u}^{2}}
$$

The cross equations covariance $\sigma_{\varepsilon, \pi x}$ between the residuals of both $\mathrm{AR}(1)$ process of inflation and of the output gap does not allow to identify either the private sector reduced form parameter $N_{Z C}$ anchoring inflation on the cost-push shock or the variance of the cost-push shock $\sigma_{\varepsilon, u}^{2}$. The simple correlation between the two residuals is predicted to be exactly negatively correlated $\left(r_{\varepsilon, \pi x}=-1\right)$ :

$$
\sigma_{\varepsilon, \pi x}=-\frac{\sigma_{\varepsilon, x}}{\sigma_{\varepsilon, \pi}} \frac{\sigma_{\varepsilon, \pi}^{2}}{\sigma_{\varepsilon, u}^{2}} \sigma_{\varepsilon, u}^{2}=-\sigma_{\varepsilon, x} \sigma_{\varepsilon, \pi}<0 .
$$

It is not possible to identify at least one of these four remaining structural parameters separately, because the identified parameter $F_{\pi, Z C}$ does not depend only on one of these 
four structural parameters:

$$
F_{\pi, Z C}=\frac{-1}{1-\beta \rho} \frac{\kappa}{\alpha_{x}}<0
$$

Three identifying equations are missing in the case of zero-credibility policy. QED.

Finally, the tests of reduced form parameters of bivariate $\operatorname{VAR}(1)$ of zero-credibility policy versus Ramsey optimal policy are not feasible. The exact multicollinearity (exact correlation) between regressors (current output gap and inflation) imply a bivariate $\operatorname{VAR}(1)$ with infinite coefficients with denominator including the term $1-r_{x \pi}^{2}$ equal to zero:

$$
\left(\begin{array}{c}
x_{t+1} \\
\pi_{t+1}
\end{array}\right)=\left(\begin{array}{cc}
+\infty & -\infty \\
-\infty & +\infty
\end{array}\right)\left(\begin{array}{c}
x_{t} \\
\pi_{t}
\end{array}\right)+\left(\begin{array}{c}
N_{Z C} \\
F_{\pi, Z C} N_{Z C}
\end{array}\right) \varepsilon_{t}
$$

The zero-credibility policy equilibrium predicts that out-of-equilibrium behavior corresponds to a non-stationary bivariate VAR including one unstable eigenvalue $\lambda_{Z C}$ and one stable eigenvalue $\rho$, which cannot be estimated. By contrast, the stationary structural VAR(1) of output gap and inflation with Ramsey optimal policy allows to identify a larger number of structural parameters.

$$
\left(\begin{array}{l}
x_{t+1} \\
\pi_{t+1}
\end{array}\right)=\left(\begin{array}{ll}
a & b \\
c & d
\end{array}\right)\left(\begin{array}{l}
x_{t} \\
\pi_{t}
\end{array}\right)+\left(\begin{array}{c}
F_{u, R} \\
0
\end{array}\right) \varepsilon_{t}
$$

Two additional reduced form parameters $(b, c)$ are available, because the stable subspace of the VAR process is of dimension two with Ramsey optimal policy instead of dimension one with zero-credibility policy.

\section{Tests with Output Gap as Policy Instrument}

\subsection{Specification tests}

The annualized quarter-on-quarter rate of inflation and the congressional budget office (CBO) measure of the output gap are taken from Mavroeidis' (2010) online appendix (detailed information at the end of this paper's appendix). The pre-Volcker sample covers the period 1960q1 to 1979q2 and the Volcker-Greenspan sample runs until 2006q2. The period of Paul Volcker's tenure is 1979q3 to 1987q2. The period of Alan Greenspan's tenure is $1987 \mathrm{q} 3$ to $2006 \mathrm{q} 1$.

According to Debortoli and Nunes (2015), a structural break corresponds to an new initial anchor of forward inflation on the output gap for Ramsey optimal policy with finite horizon. Clarida, Gali and Gertler (2000) and Mavroeidis (2010) consider the beginning of Paul Volcker's mandate 1979q3 as a structural break. Givens (2012) considers 1982q1 as a structural break, after 1981 fall of inflation and before the 1982 recession. Matthes (2015) estimation of the private sectors beliefs regarding central bank regimes also points to $1982 \mathrm{q} 1$ as a structural break. Table 2 presents summary statistics before and after the $1979 \mathrm{q} 3$ and $1982 \mathrm{q} 1$ structural breaks.

Table 2: Summary statistics of inflation and output gap 


\begin{tabular}{|c|c|c|c|c|c|c|c|c|c|c|}
\hline & dates & obs. & mean & $\min$ & $\max$ & after: & obs. & mean & min & $\max$ \\
\hline$\pi_{t}$ & $<79 q 3$ & 78 & $\begin{array}{c}4.39 \\
(2.71)\end{array}$ & 0.59 & 11.79 & $\geq 79 q 3$ & 108 & $\begin{array}{c}3.18 \\
(2.03)\end{array}$ & 0.64 & 10.93 \\
\hline$x_{t}$ & $<79 q 3$ & 78 & $\begin{array}{c}0.47 \\
(2.59)\end{array}$ & -4.97 & 6.10 & $\geq 79 q 3$ & 108 & $\begin{array}{c}-1.11 \\
(2.07)\end{array}$ & -7.95 & 3.01 \\
\hline$\pi_{t}$ & $<82 q 1$ & 88 & $\begin{array}{c}4.86 \\
(2.90)\end{array}$ & 0.59 & 11.79 & $\geq 82 q 1$ & 98 & $\begin{array}{c}2.64 \\
(1.08)\end{array}$ & 0.64 & 5.61 \\
\hline$x_{t}$ & $<82 q 1$ & 88 & $\begin{array}{c}0.20 \\
(2.59)\end{array}$ & -4.97 & 6.10 & $\geq 79 q 3$ & 98 & $\begin{array}{c}-1.03 \\
(2.12)\end{array}$ & -7.95 & 3.01 \\
\hline
\end{tabular}

Standard deviations are in parentheses.

The mean of inflation and of output gap are lower during Volcker-Greenspan than before Volcker. Excluding the period 1979q3 to 1981q4, in particular the sharp disinflation which occurred during 1981 (figure 3), the standard error of inflation decreases by half from 2.03 to 1.08 .

Table 3: Pre-tests of zero-credibility policy rule

\begin{tabular}{|c|c|c|c|c|c|c|c|c|}
\hline Dates & obs & $r_{x \pi}$ & Low 95\% $r$ & $p$ & $R_{x \pi}^{2}$ & $F_{\pi, Z C}$ & $c$ & $\rho_{\varepsilon, x \pi}$ \\
\hline$<79 q 3$ & 78 & -0.13 & -0.21 & $<0.001$ & 0.02 & $\begin{array}{c}-0.13 \\
(0.11)\end{array}$ & $\begin{array}{c}1.03 \\
(0.56)\end{array}$ & $\begin{array}{c}\mathbf{0 . 9 2} \\
(0.04)\end{array}$ \\
\hline$<82 q 1$ & 108 & -0.30 & -0.42 & $<0.001$ & 0.09 & $\begin{array}{c}-0.30 \\
(0.09)\end{array}$ & $\begin{array}{c}-0.14 \\
(0.35)\end{array}$ & $\begin{array}{c}\mathbf{0 . 9 1} \\
(0.04)\end{array}$ \\
\hline$\geq 79 q 3$ & 88 & -0.24 & -0.31 & $<0.001$ & 0.06 & $\begin{array}{c}-\mathbf{0 . 2 2} \\
(0.09)\end{array}$ & $\begin{array}{c}1.25 \\
(0.53)\end{array}$ & $\begin{array}{c}\mathbf{0 . 9 2} \\
(0.05)\end{array}$ \\
\hline$\geq 82 q 1$ & 98 & -0.40 & -0.53 & $<0.001$ & 0.16 & $\begin{array}{c}-0.78 \\
(0.18)\end{array}$ & $\begin{array}{c}1.03 \\
(0.52)\end{array}$ & $\begin{array}{c}\mathbf{0 . 8 9} \\
(0.05)\end{array}$ \\
\hline
\end{tabular}

The pre-tests of the null hypothesis of a quasi perfect negative correlation $H_{0}: r_{x \pi}<$ -0.99 between observed inflation and observed output gap are rejected. The test uses Fisher's $Z$ transformation using the procedure corr with the software SAS. The threshold of the composite null hypothesis -0.99 is far away from the $95 \%$ single tail confidence interval, where the lowest $95 \%$ confidence limit reported in table 3 is at most equal to -0.53 for the period beginning from 1982q1 (figure 4). The opposite null hypothesis $H_{0}: r\left(x_{t}, \pi_{t}\right)=0$ is not rejected before $1979 \mathrm{q} 3$. zero-credibility policy predicts a perfect correlation for the anchor of inflation expectations with the output gap. If the zerocredibility policy equilibrium occurred before $1979 \mathrm{q} 3$, we do not reject the null hypothesis $H_{0}: r\left(E_{t-1}\left(\pi_{t}\right), \pi_{t}\right)=0$ that the rational expectations of inflation are orthogonal to observed inflation.

The pre-tests of the null hypothesis of the auto-correlation of residuals $H_{0}: \rho_{\varepsilon, x \pi}=0$ are strongly rejected, with a point estimate at least equal to 0.89 (figure 5). These tests gives a hint of model misspecification. They suggest an omitted lagged policy instrument in the policy rule. When it is included in Ramsey optimal policy rule, the $R^{2}$ increases from $16 \%$ (table 3, last line) to $93 \%$ (table 6, last line) beginning in 1982q1.

Table 4: Auto-correlation of inflation and output gap 


\begin{tabular}{|c|c|c|c|c|c|c|c|c|c|c|}
\hline dates & obs. & var. & $r$ & $R^{2}$ & $\rho$ & $c$ & $\sigma_{\varepsilon}$ & $\rho_{\varepsilon}$ & $D F$ & $P P$ \\
\hline$<79 q 3$ & 78 & $\pi_{t}$ & 0.86 & 0.74 & $\begin{array}{c}0.88 \\
(0.06)\end{array}$ & $\begin{array}{c}0.62 \\
(0.30)\end{array}$ & 1.38 & $\begin{array}{c}-0.22 \\
(0.12)\end{array}$ & 0.55 & 0.41 \\
\hline$<79 q 3$ & 78 & $x_{t}$ & 0.93 & 0.86 & $\begin{array}{c}0.93 \\
(0.04)\end{array}$ & $\begin{array}{c}0.03 \\
(0.11)\end{array}$ & 0.99 & $\begin{array}{c}0.26 \\
(0.11)\end{array}$ & 0.20 & 0.33 \\
\hline$<82 q 1$ & 88 & $\pi_{t}$ & 0.88 & 0.78 & $\begin{array}{c}0.88 \\
(0.05)\end{array}$ & $\begin{array}{c}0.63 \\
(0.28)\end{array}$ & 1.35 & $\begin{array}{c}-0.19 \\
(0.11)\end{array}$ & 0.34 & 0.23 \\
\hline$<82 q 1$ & 88 & $x_{t}$ & 0.92 & 0.85 & $\begin{array}{c}0.93 \\
(0.04)\end{array}$ & $\begin{array}{c}-0.03 \\
(0.11)\end{array}$ & 1.03 & $\begin{array}{c}0.23 \\
(0.11)\end{array}$ & 0.27 & 0.37 \\
\hline$\geq 79 q 3$ & 108 & $\pi_{t}$ & 0.89 & 0.79 & $\begin{array}{c}0.85 \\
(0.04)\end{array}$ & $\begin{array}{c}0.42 \\
(0.16)\end{array}$ & 0.93 & $\begin{array}{c}-0.27 \\
(0.09)\end{array}$ & 0.04 & 0.01 \\
\hline$\geq 79 q 3$ & 108 & $x_{t}$ & 0.94 & 0.88 & $\begin{array}{c}0.94 \\
(0.03)\end{array}$ & $\begin{array}{c}-0.07 \\
(0.08)\end{array}$ & 0.70 & $\begin{array}{c}0.34 \\
(0.09)\end{array}$ & 0.11 & 0.25 \\
\hline$\geq 82 q 1$ & 98 & $\pi_{t}$ & $\mathbf{0 . 6 4}$ & 0.41 & $\begin{array}{c}\mathbf{0 . 5 9} \\
(0.07)\end{array}$ & $\begin{array}{c}1.06 \\
(0.21)\end{array}$ & 0.83 & $\begin{array}{c}-\mathbf{0 . 2 0} \\
(0.10)\end{array}$ & $\mathbf{0 . 0 0}$ & $\mathbf{0 . 0 0}$ \\
\hline$\geq 82 q 1$ & 98 & $x_{t}$ & $\mathbf{0 . 9 6}$ & 0.92 & $\begin{array}{c}\mathbf{0 . 9 5} \\
(0.03)\end{array}$ & $\begin{array}{c}-0.02 \\
(0.07)\end{array}$ & 0.60 & $\begin{array}{c}\mathbf{0 . 3 5} \\
(0.09)\end{array}$ & $\mathbf{0 . 0 7}$ & $\mathbf{0 . 3 5}$ \\
\hline
\end{tabular}

Table 4 investigates the auto-correlation and unit roots of inflation and output gap. The output gap and inflation are highly auto-correlated (respectively 0.93 and 0.86 ), except when inflation excludes the 1981 disinflation for the period after 1981q4. For the period $1982 \mathrm{q} 1$ to $2006 \mathrm{q} 2$, the inflation auto-correlation coefficient falls in the $95 \%$ confidence interval $0.6 \pm 0.14$ and it is statistically different from the output gap autocorrelation coefficient in the $95 \%$ confidence interval $0.95 \pm 0.06$ (figures 4 and 5). As the zero-credibility policy equilibrium predicts that the auto-correlation of the output gap and of inflation should be the same, this is an additional test against zero-credibility policy, which holds for the period 1982q1 to 2006q2.

There is a negative auto-correlation of residuals $\rho_{\varepsilon}$ for inflation and a (statistically significant at the $5 \%$ level) positive auto-correlation of residuals for the output gap. The column DF reports the p-value of the Dickey-Fuller test of unit root with one lag without trend. The column PP reports the p-value of the Phillips-Perron test of unit root, which takes into account auto-correlation, with one lag without trend. The null hypothesis of a unit root is rejected for inflation after $1979 \mathrm{q} 2$ and after $1981 \mathrm{q} 4$.

\subsection{Tests of Ramsey Optimal Policy}

Table 5 presents estimates of structural parameters, Table 5 report estimates of three structural VAR estimations for $\left(\rho, \lambda_{R}, F_{\pi, R}\right),\left(\rho, \lambda_{R}, \frac{\alpha_{x}}{\kappa}\right)$ and $\left(\rho, \kappa(\beta), \alpha_{x}(\beta)\right)$ with two given values for the discount factor $\beta=1$ or $\beta=0.99$ for the Volcker-Greenspan period. With these three estimations, delta method is not necessary to compute the standard errors of parameters in each case. Maximum likelihood did not converge for pre-Volcker period (unconstrained VAR corresponds to complex conjugate eigenvalues, which are excluded because of exogenous real auto-correlation of cost-push shock). Post 1982q1 estimations converged to unlikely estimates.

Table 5: Ramsey optimal policy structural parameters

\begin{tabular}{|c|c|c|c|c|c|c|c|c|c|}
\hline Dates & $\rho$ & $\lambda$ & $F_{\pi}$ & $\frac{\alpha_{x}}{\kappa}=\frac{1}{\varepsilon}$ & $\beta$ & $\kappa(\beta)$ & $\alpha_{x}(\beta)$ & $F_{u, R}(\beta)$ & $\sigma_{u}(\beta)$ \\
\hline$\geq 79 q 3$ & $\begin{array}{l}0.995^{*} \\
(0.024)\end{array}$ & $\begin{array}{c}0.857^{*} \\
(0.054)\end{array}$ & $\begin{array}{c}0.447 \\
(0.292)\end{array}$ & $\begin{array}{c}13.375^{*} \\
(6.627)\end{array}$ & 1 & $\begin{array}{c}0.321 \\
(0.303)\end{array}$ & $\begin{array}{c}4.296 \\
(5.447)\end{array}$ & -3.027 & 0.229 \\
\hline$\geq 79 q 3$ & $\begin{array}{l}0.995^{*} \\
(0.024)\end{array}$ & $\begin{array}{c}0.857^{*} \\
(0.054)\end{array}$ & $\begin{array}{l}0.447 \\
(0.292)\end{array}$ & $\begin{array}{c}13.375^{*} \\
(6.627)\end{array}$ & 0.99 & $\begin{array}{c}0.340 \\
(0.314)\end{array}$ & $\begin{array}{c}4.552 \\
(5.703)\end{array}$ & -2.861 & 0.242 \\
\hline
\end{tabular}

The cost-push shock faces is extremely persistent, close to a unit root, with $\rho$ estimate close to one. The ratio $\frac{\alpha_{x}}{\kappa}$ is statistically significant. If the Fed's preferences are identical to (welfare) household's preferences), then $\frac{\alpha_{x}}{\kappa}=\frac{1}{\varepsilon}$ and $\widehat{\varepsilon}=0.07$. The new-Keynesian Phillips curve parameter $\kappa$ is relatively large. The Fed's preference parameter $\alpha_{x}$ is 
relatively large (although not unheard of in previous estimations). for the period 19792006.

Table 6: Inflation and output gap structural (S) versus unconstrained (U) VAR

\begin{tabular}{|c|c|c|c|c|c|c|c|c|c|}
\hline dates & obs. & var. & $\mathrm{S} / \mathrm{U}$ & $\pi_{t-1}$ & $x_{t-1}$ & $c$ & $\rho_{\varepsilon}$ & $R^{2}$ & $\lambda$ \\
\hline$\geq 79 q 3$ & 108 & $\pi_{t}$ & $\mathrm{~S}$ & 0.85 & 0.009 & $\begin{array}{c}0.428 \\
(0.16)\end{array}$ & $\begin{array}{c}-0.25 \\
(0.09)\end{array}$ & 0.793 & $\begin{array}{c}0.857^{*} \\
(0.054)\end{array}$ \\
\hline$\geq 79 q 3$ & 108 & $\pi_{t}$ & $\mathrm{U}$ & $\begin{array}{c}0.85 \\
(0.04)\end{array}$ & $\begin{array}{c}0.009 \\
(0.04)\end{array}$ & $\begin{array}{c}0.43 \\
(0.16)\end{array}$ & $\begin{array}{c}-0.25 \\
(0.09)\end{array}$ & 0.79 & 0.85 \\
\hline$\geq 79 q 3$ & 108 & $x_{t}$ & $\mathrm{~S}$ & -0.064 & $\mathbf{0 . 9 9 9}$ & $\begin{array}{c}0.198 \\
(0.121)\end{array}$ & $\begin{array}{c}0.29 \\
(0.09)\end{array}$ & 0.888 & $\begin{array}{c}\mathbf{0 . 9 9 5} \\
(0.024)\end{array}$ \\
\hline$\geq 79 q 3$ & 108 & $x_{t}$ & $\mathrm{U}$ & $\begin{array}{c}-0.084 \\
(0.03)\end{array}$ & $\begin{array}{c}0.917 \\
(0.03)\end{array}$ & $\begin{array}{c}0.17 \\
(0.11)\end{array}$ & $\begin{array}{c}0.29 \\
(0.09)\end{array}$ & 0.89 & 0.92 \\
\hline
\end{tabular}

Table 6 compares the reduced form parameters of the VAR of Ramsey optimal policy with parameters of an unconstrained VAR. The inflation equation of the VAR are the same up to the third decimal of all statistics. For the output gap equation, Ramsey optimal policy slightly over-estimates the persistence of the output gap: its VAR autocorrelation parameter shifts from 0.93 to 1 . For the output gap rule, the auto-correlation of residuals fell from 0.92 with zero-credibility policy to 0.29 with Ramsey optimal policy, but it remains statistically significant. As well, the inflation equation has a statistically significant auto-correlation $(-0.25)$.

The reduced form Ramsey optimal policy rule of the structural VAR is observationally equivalent to the LQR first step representation including the non-observable cost-push shock, when taking into account the other equations of the Hamiltonian system:

$$
\text { Ramsey : } x_{t}=0.995 x_{t-1}-0.064 \pi_{t-1}-2.861 \varepsilon_{u, t} \text { or } x_{t}=0.447 \pi_{t}-2.861 u_{t} \text { for } \beta=0.99
$$

The policy instrument responds to two variables for Ramsey stable subspace of dimension two. The policy instrument responds to one variable in the zero-credibility policy stable subspace of dimension one. The reduced form policy rule for zero-credibility policy is:

Time-consistent: $x_{t}=-0.22 \pi_{t}$

\section{Tests with Federal Funds Rate Smoothing and Work- ing Capital Channel}

\subsection{Specification tests}

Assuming the polar case where all labor cost is financed by working capital instead than no labor cost at all, the federal funds rate is used here as a policy instrument. Its variance enters into the period loss function $\pi_{t}^{2}+\alpha_{i} i_{t}^{2}$ as an interest smoothing model. Figure 2 represents the time series of inflation and federal funds rate. Table 2 presents summary statistics before and after the 1979q3 and 1982q1 structural breaks.

Table 2B: Summary statistics of inflation and federal funds rate 


\begin{tabular}{|c|c|c|c|c|c|c|c|c|c|c|}
\hline & dates & obs. & mean & $\min$ & $\max$ & after: & obs. & mean & $\min$ & $\max$ \\
\hline$\pi_{t}$ & $<79 q 3$ & 78 & $\begin{array}{c}4.39 \\
(2.71)\end{array}$ & 0.59 & 11.79 & $\geq 79 q 3$ & 108 & $\begin{array}{c}3.18 \\
(2.03)\end{array}$ & 0.64 & 10.93 \\
\hline$i_{t}$ & $<79 q 3$ & 78 & $\begin{array}{c}5.47 \\
(2.42)\end{array}$ & 1.68 & 12.09 & $\geq 79 q 3$ & 108 & $\begin{array}{c}6.56 \\
(3.76)\end{array}$ & 1.00 & 17.78 \\
\hline$\pi_{t}$ & $<82 q 1$ & 88 & $\begin{array}{c}4.86 \\
(2.90)\end{array}$ & 0.59 & 11.79 & $\geq 82 q 1$ & 98 & $\begin{array}{c}2.64 \\
(1.08)\end{array}$ & 0.64 & 5.61 \\
\hline$i_{t}$ & $<82 q 1$ & 88 & $\begin{array}{c}6.84 \\
(3.74)\end{array}$ & 1.68 & 17.78 & $\geq 79 q 3$ & 98 & $\begin{array}{c}5.76 \\
(2.84)\end{array}$ & 1.00 & 14.51 \\
\hline
\end{tabular}

Standard deviations are in parentheses below the mean.

The means of inflation are lower after Volcker than before Volcker. Excluding the period 1979q3 to 1981q4, in particular the sharp disinflation which occurred during 1981 (figure 3), the standard error of inflation decreases by half from 2.03 to 1.08 . The difference of means between the policy interest rate and inflation increased after Volcker.

Table 3B: Pre-test of zero-credibility policy rule

\begin{tabular}{|c|c|c|c|c|c|c|c|c|}
\hline dates & obs & $r_{i \pi}$ & $t$ & $r_{i \pi}=0: p$ & $R_{i \pi}^{2}$ & $F_{\pi, D}$ & $c$ & $\rho_{\varepsilon, i \pi}$ \\
\hline$<79 q 3$ & 78 & 0.83 & 12.85 & $<0.001$ & 0.68 & $\begin{array}{c}0.74 \\
(2.22)\end{array}$ & $\begin{array}{c}2.22 \\
(0.30)\end{array}$ & $\begin{array}{c}0.61 \\
(0.09)\end{array}$ \\
\hline$<82 q 1$ & 88 & 0.79 & 11.83 & $<0.001$ & 0.62 & $\begin{array}{c}1.01 \\
(0.08)\end{array}$ & $\begin{array}{c}1.55 \\
(0.48)\end{array}$ & $\begin{array}{c}0.73 \\
(0.08)\end{array}$ \\
\hline$\geq 79 q 3$ & 108 & 0.75 & 11.63 & $<0.001$ & 0.56 & $\begin{array}{c}1.39 \\
(0.12)\end{array}$ & $\begin{array}{c}1.39 \\
(0.11)\end{array}$ & $\begin{array}{c}0.76 \\
(0.06)\end{array}$ \\
\hline$\geq 82 q 1$ & 98 & 0.53 & 6.08 & $<0.001$ & 0.28 & $\begin{array}{c}1.39 \\
(0.22)\end{array}$ & $\begin{array}{c}2.09 \\
(0.65)\end{array}$ & $\begin{array}{c}0.80 \\
(0.06)\end{array}$ \\
\hline
\end{tabular}

The tests of the null hypothesis of a quasi perfect negative correlation $H_{0}: r_{i \pi}<-0.99$ between inflation and federal funds rate have been replaced by the usual tests of the null hypothesis: $H_{0}: r_{i \pi}=0$, because $r_{i \pi}>0$. The negative sign of the zero-credibility policy rule is rejected, with large $t$ statistics. The Durbin and Breusch-Godfrey tests strongly reject the lack of serial correlation (for one or two lags) with p-value below $10^{-4}$. Tests of the null hypothesis of the first order auto-correlation of residuals $H_{0}: \rho_{\varepsilon, i \pi}=0$ are rejected, with a point estimate at least equal to 0.60 and at most 0.80 . The infinite horizon zero-credibility positive-feedback mechanism does not fit the data when the cost of capital is taken into account into the monetary transmission mechanism. Finally, the Taylor principle (an inflation coefficient $F_{\pi}$ larger than one) is not satisfied before Volcker and satisfied after Volcker.

Table 4B investigates the auto-correlation of inflation and federal funds rate. Inflation and Federal funds rate are highly auto-correlated (respectively 0.93 and 0.86), except for the period $1982 \mathrm{q} 1$ to $2006 \mathrm{q} 2$, the inflation auto-correlation coefficient falls in the $95 \%$ confidence interval $0.6 \pm 0.14$ and it is statistically different from the federal funds rate auto-correlation coefficient in the $95 \%$ confidence interval $0.95 \pm 0.02$. Infinite horizon zero-credibility policy predict that the auto-correlation should be the same, which is not the case after $1982 \mathrm{q} 1$.

Table 4B. Auto-correlation of inflation and federal funds rate 


\begin{tabular}{|c|c|c|c|c|c|c|c|c|c|c|}
\hline dates & obs. & var. & $r$ & $R^{2}$ & $\rho$ & $c$ & $\sigma_{\varepsilon}$ & $\rho_{\varepsilon}$ & $D F$ & $P P$ \\
\hline$<79 q 3$ & 78 & $\pi_{t}$ & 0.86 & 0.74 & $\begin{array}{c}0.88 \\
(0.06)\end{array}$ & $\begin{array}{c}0.62 \\
(0.30)\end{array}$ & 1.38 & $\begin{array}{c}-0.22 \\
(0.12)\end{array}$ & 0.55 & 0.41 \\
\hline$<79 q 3$ & 78 & $i_{t}$ & 0.93 & 0.87 & $\begin{array}{c}0.95 \\
(0.04)\end{array}$ & $\begin{array}{c}0.33 \\
(0.25)\end{array}$ & 0.89 & $\begin{array}{c}0.43 \\
(0.10)\end{array}$ & 0.17 & 0.54 \\
\hline$<82 q 1$ & 88 & $\pi_{t}$ & 0.88 & 0.78 & $\begin{array}{c}0.88 \\
(0.05)\end{array}$ & $\begin{array}{c}0.63 \\
(0.28)\end{array}$ & 1.35 & $\begin{array}{c}-0.19 \\
(0.11)\end{array}$ & 0.34 & 0.23 \\
\hline$<82 q 1$ & 88 & $i_{t}$ & 0.94 & 0.89 & $\begin{array}{c}0.96 \\
(0.04)\end{array}$ & $\begin{array}{c}0.36 \\
(0.27)\end{array}$ & 1.26 & $\begin{array}{c}0.21 \\
(0.11)\end{array}$ & 0.42 & 0.65 \\
\hline$\geq 79 q 3$ & 108 & $\pi_{t}$ & 0.89 & 0.79 & $\begin{array}{c}0.85 \\
(0.04)\end{array}$ & $\begin{array}{c}0.42 \\
(0.16)\end{array}$ & 0.93 & $\begin{array}{c}-0.27 \\
(0.09)\end{array}$ & 0.04 & 0.01 \\
\hline$\geq 79 q 3$ & 108 & $i_{t}$ & 0.94 & 0.92 & $\begin{array}{c}0.96 \\
(0.03)\end{array}$ & $\begin{array}{c}0.23 \\
(0.20)\end{array}$ & 1.05 & $\begin{array}{c}0.15 \\
(0.09)\end{array}$ & 0.38 & 0.44 \\
\hline$\geq 82 q 1$ & 98 & $\pi_{t}$ & $\mathbf{0 . 6 4}$ & 0.41 & $\begin{array}{c}0.59 \\
(0.07)\end{array}$ & $\begin{array}{c}1.06 \\
(0.21)\end{array}$ & 0.83 & $\begin{array}{c}-0.20 \\
(0.10)\end{array}$ & 0.00 & 0.00 \\
\hline$\geq 82 q 1$ & 98 & $i_{t}$ & 0.96 & 0.95 & $\begin{array}{c}0.94 \\
(0.02)\end{array}$ & $\begin{array}{c}0.26 \\
(0.14)\end{array}$ & 0.63 & $\begin{array}{c}0.45 \\
(0.09)\end{array}$ & 0.18 & 0.08 \\
\hline
\end{tabular}

There is a negative auto-correlation of residuals $\rho_{\varepsilon}$ for inflation and a positive autocorrelation of residuals for federal funds rate. The column DF reports the $p$-value of the Dickey-Fuller test of unit root with one lag without trend. The column PP reports the $p$-value of the Phillips-Perron test of unit root, which takes into account auto-correlation, with one lag without trend. The null hypothesis of a unit root is rejected at the $5 \%$ threshold for inflation after 1979q2 and after 1981q4. It is rejected for federal funds rate at the $10 \%$ level after 1981q4 only for the Phillips-Perron test.

\subsection{Tests of Ramsey optimal policy}

Table 5B reports estimates using four structural VAR estimations for $\left(\rho, \lambda_{C}, F_{\pi, C}\right)$, for $\left(\rho, \lambda_{C}, \frac{\alpha_{i}}{\kappa_{i}}\right)$ and for $\left(\rho, \kappa(\beta), \alpha_{i}(\beta)\right)$ with the identification restrictions for the credibility adjusted discount factor. We check that these three estimations are observationally equivalent. In particular, each estimate satisfy the theoretical relations with the others implied by Ramsey optimal policy. When the federal funds rate is the policy instrument, the estimations only converged to plausible values for the pre-Volcker period, before $1979 \mathrm{q} 3$. The implicit rule parameter on the cost-push shock is computed using $F_{u}(\beta)=\frac{-1}{1-\beta \rho \lambda} F_{\pi}$ and the variance of the cost push shock is $\sigma_{u}(\beta)=\frac{\sigma_{\varepsilon, i}}{-F_{u}(\beta)}$ with the root mean square error of the residuals of the policy instrument equation equal to $\sigma_{\varepsilon, i}=0.876$.

Table 5B: Ramsey optimal policy structural parameters

\begin{tabular}{|c|c|c|c|c|c|c|c|c|c|}
\hline Dates & $\rho$ & $\lambda$ & $F_{\pi}$ & $\frac{\alpha_{i}}{\kappa}$ & $\beta$ & $\kappa_{i}(\beta)$ & $\alpha_{i}(\beta)$ & $F_{u, C}(\beta)$ & $\sigma_{u}(\beta)$ \\
\hline$<79 q 3$ & $0.550^{*}$ & $0.947^{*}$ & $0.873^{*}$ & 20.83 & 1 & 0.060 & $1.24^{*}$ & -1.822 & 0.481 \\
$(0.092)$ & $(0.047)$ & $(0.131)$ & $(18.26)$ & & $(0.06)$ & $(0.34)$ & \\
\hline$<79 q 3$ & $0.550^{*}$ & - & - & - & 0.99 & $\begin{array}{c}0.071 \\
(0.06)\end{array}$ & $\begin{array}{c}1.47^{*} \\
(0.36)\end{array}$ & -1.802 & 0.486 \\
\hline$<79 q 3$ & $\begin{array}{c}0.550^{*} \\
(0.092)\end{array}$ & - & - & - & 0.94 & $\begin{array}{c}0.125^{*} \\
(0.063)\end{array}$ & $\begin{array}{c}2.60^{*} \\
(0.16)\end{array}$ & -1.710 & 0.512 \\
\hline$<79 q 3$ & $\begin{array}{c}0.550^{*} \\
(0.092)\end{array}$ & - & - & - & 0.93 & $\begin{array}{c}0.136^{*} \\
(0.064)\end{array}$ & $\begin{array}{c}2.83^{*} \\
(1.35)\end{array}$ & -1.693 & 0.517 \\
\hline$<79 q 3$ & $0.550^{*}$ \\
$0.092)$ & - & - & - & 0.92 & $\begin{array}{c}0.146^{*} \\
(0.065)\end{array}$ & $\begin{array}{c}3.05^{*} \\
(1.54)\end{array}$ & -1.676 & 0.522 \\
\hline
\end{tabular}

Estimates of structural parameters are plausible values. The Fed's reduced form rule parameter $F_{\pi}$ is significantly different from zero at the $5 \%$. To reach the statistical significance at the $5 \%$ level of both $\kappa_{i}(\beta)$ and $\alpha_{i}(\beta)$ and not only one of the two parameters is obtained for identification restrictions of the credibility adjusted discount factor $\beta \in[0.92,0.94]$. This corresponds to a Fed's probability to commit in this range: $q \in[0.93,0.95]$ for an identification restriction of the discount factor 0.99 . For $\beta>0.94$, 
only the Fed's preference $\alpha_{i}(\beta)$ is statistically significant. For $\beta<0.92$, only the slope of the new-Keynesian Phillips curve for working capital $\kappa_{i}(\beta)$ is statistically significant. When the identification restriction on $\beta$ increases, both estimates $\kappa_{i}(\beta)$ and $\alpha_{i}(\beta)$ increase, but not at the same pace.

Table $6 \mathrm{~B}$ shows that the reduced form parameters of the structural VAR(1) (rows $\mathrm{S}$ ) are identical to the unconstrained $\operatorname{VAR}(1)$ estimates (rows $\mathrm{U}$ ) up to the third decimal.

Table 6B: Inflation and federal funds rate structural (S) versus unconstrained (U) VAR

\begin{tabular}{|c|c|c|c|c|c|c|c|c|c|c|}
\hline dates & obs. & var. & $\mathrm{S} / \mathrm{U}$ & $\pi_{t-1}$ & $i_{t-1}$ & $c$ & $\rho_{\varepsilon}$ & $R^{2}$ & $\Delta R^{2}$ & $\lambda$ \\
\hline$<79 q 3$ & 77 & $\pi_{t}$ & S & 0.521 & 0.488 & $\begin{array}{c}-0.471 \\
(0.340)\end{array}$ & $\begin{array}{c}-0.12 \\
(0.16)\end{array}$ & 0.804 & 0.06 & $\begin{array}{c}0.550^{*} \\
(0.092)\end{array}$ \\
\hline$<79 q 3$ & 77 & $\pi_{t}$ & $\mathrm{U}$ & $\begin{array}{l}0.52 \\
(0.09)\end{array}$ & $\begin{array}{l}0.49 \\
(0.10)\end{array}$ & $\begin{array}{c}-0.471 \\
(0.343)\end{array}$ & $\begin{array}{c}-0.12 \\
(0.16)\end{array}$ & 0.804 & 0.06 & 0.550 \\
\hline$<79 q 3$ & 77 & $i_{t}$ & $\mathrm{~S}$ & -0.025 & 0.976 & $\begin{array}{l}0.316 \\
(0.226)\end{array}$ & $\begin{array}{l}0.55 \\
(0.12)\end{array}$ & 0.869 & 0.01 & $\begin{array}{c}0.947^{*} \\
(0.047)\end{array}$ \\
\hline$<79 q 3$ & 77 & $i_{t}$ & $\mathrm{U}$ & $\begin{array}{c}-0.025 \\
(0.065)\end{array}$ & $\begin{array}{c}0.976 \\
(0.07)\end{array}$ & $\begin{array}{l}0.317 \\
(0.252)\end{array}$ & $\begin{array}{l}0.55 \\
(0.12)\end{array}$ & 0.869 & 0.01 & 0.947 \\
\hline
\end{tabular}

(1) For the inflation equation, there is Granger causality from lagged federal funds rate to inflation. The exogenous cost-push shock auto-correlation is close to the autocorrelation of inflation in the VAR. The residuals are not auto-correlated controlling for endogenous lagged inflation and federal funds according to Durbin's test. The autocorrelation estimate is -0.12 , It not statistically different from zero (Durbin's test: $t=-0.77$, $p=0.44)$.

(2) For the federal funds rate rule equation, the auto-correlation 0.976 is relatively close to a unit root. The endogenous stable eigenvalue corresponds to the auto-correlation of the federal funds rate.

One can compare our modest results with two recent papers using implicit functions of the parameters within a reduced form VAR including three US time-series (inflation, output gap and Federal funds rate). Givens (2012) finds out that Volcker-Greenspan period corresponds to zero-credibility policy whereas Matthes (2015) finds it corresponds to Ramsey optimal policy. The ratio of the estimated weight on output in the loss function in commitment versus discretion in Givens (2012): $\widehat{\lambda}_{D} / \widehat{\lambda}_{C}=0.0987 / 0.1351=0.7$ and 10 times larger in Matthes $(2015) \widehat{\lambda}_{D} / \widehat{\lambda}_{C}=0.49 / 0.07=7$. For the transmission mechanism, Givens (2012) estimate of the intertemporal elasticity of substitution is 0.0089 (estimated standard error 0.0035, 95\% confidence interval [0.0019,0.0159]) for Ramsey optimal policy and 0.0002 for zero-credibility policy, with an estimated standard error 0.0001 so that zero belong to the $95 \%$ confidence interval. Matthes (2015) estimate is 70 times larger $1 / 1.61=0.62$ for both policies. The estimated standard error of this parameter is not disclosed. Givens (2012) estimate of the slope of the new-Keynesian Phillips curve is $\widehat{\kappa}=0.0045$, with estimated standard error 0.0016 and $95 \%$ confidence interval $[0.0019,0.0159])$, for Ramsey optimal policy and 0.0047 for discretion with estimated standard error 0.009 so that zero belongs to the $95 \%$ confidence interval ("Estimates of $\kappa$ are small but within the range typical of the literature." p.1043). In the discretion regime, both transmission mechanism parameters for the Federal funds rate not statistically different from zero. This result supports the hypothesis of monetary policy ineffectiveness during 1982-2006. Matthes (2015) estimate is 75 times larger: $\widehat{\kappa}=0.7 /(1+0.99)=$ 0.35: "The estimate found here, while being at the other end, is not unheard of". The estimated standard error of this parameter is not disclosed.

Givens (2012) assumes one lag of inflation, two lags of output and one lag for Federal funds rate. Matthes (2015) assumes one lag of inflation and two exogenous auto-regressive 
forcing variables. The more lags of observable exogenous variables are added in the specification of the new-Keynesian Phillips curve, the more likely the weak identification of some parameters occurs (Mavroeidis (2005), Mavroeidis et al. (2014), Dees, Pesaran, Smith, Smith (2009), Canova and Sala (2009), Komunjer and Ng (2012) and Iskrev (2012)).

\section{Conclusion}

Using closed form solutions of Ramsey optimal policy and zero-credibility policy, we take exactly into account the identification restrictions related to the dimension of the stable subspace of each policy. Ramsey optimal policy with quasi-commitment has a comparative advantage with respect to infinite horizon zero-credibility policy for modelling persistence with fewer parameters. Further work may extend this approach to other transmission mechanisms than the new-Keynesian Phillips curve with labor cost channel or with working capital channel.

\section{References}

[1] Adjemian S. and Devulder A. (2011). Evaluation de la politique monétaire dans un modèle DSGE pour la zone euro. Revue française d'économie, 26(1), 201-245.

[2] Adolfson, M., Laséen, S., Lindé, J., \& Svensson, L. E. (2011). Optimal Monetary Policy in an Operational Medium-Sized DSGE Model. Journal of Money, Credit and Banking, 43(7), 1287-1331.

[3] Anderson E.W., Hansen L.P., McGrattan E.R. and Sargent T.J. (1996). Mechanics of Forming and Estimating Dynamic Linear Economies. in Amman H.M., Kendrick D.A. and Rust J. (editors) Handbook of Computational Economics, Elsevier, Amsterdam, 171-252.

[4] Backus, D., \& Driffill, J. (1986). The consistency of optimal policy in stochastic rational expectations models (No. 124). CEPR Discussion Papers.

[5] Blanchard O.J. and Kahn C. (1980). The solution of linear difference models under rational expectations. Econometrica, 48, pp. 1305-1311.

[6] Blinder A.S. (1986). More on the speed of adjustment in inventory models. Journal of Money, Credit and Banking, 18, 355-365.

[7] Bratsiotis, G. J. and Robinson, W. A. (2016). Unit Total Costs: An Alternative Marginal Cost Proxy for Inflation Dynamics. Macroeconomic Dynamics, 1-24.

[8] Canova, F., \& Sala, L. (2009). Back to square one: Identification issues in DSGE models. Journal of Monetary Economics, 56(4), 431-449.

[9] Castelnuovo E. and Surico P. (2004). Model uncertainty, optimal monetary policy and the preferences of the Fed. Scottish Journal of Political Economy, 51(1), pp. 105-126. 
[10] Castelnuovo E. (2006). The Fed's preferences for Policy Rate Smoothing: Overestimation due to misspecification? The B.E. Journal in Macroeconomics (Topics), $6(2)$, article 5 .

[11] Cecchetti S. and Ehrmann M. (2002), "Does Inflation Targeting Increase Output Volatility? An International Comparison of Policymakers Preferences and Outcomes," in Loayza, Norman, and Klaus Schmidt-Hebbel (eds.), Monetary Policy: Rules and Transmission Mechanisms, vol. 4 of Series on Central Banking, Analysis, and Economic Policies, Central Bank of Chile, 247-274.

[12] Chatelain, J. B., and Ralf, K. (2017a). Publish and Perish: Creative Destruction and Macroeconomic Theory. Available at SSRN: https://ssrn.com/abstract=2915860.

[13] Chatelain, J. B., and Ralf, K. (2017b). Hopf bifurcation from newKeynesian Taylor rule to Ramsey optimal policy (2017). Available at SSRN: https://papers.ssrn.com/sol3/papers.cfm?abstract_id=2971227.

[14] Chatelain, J. B., and Ralf, K. (2017c). A Simple Algorithm for Solving Ramsey Optimal Policy with Exogenous Forcing Variables. Econstor working paper.

[15] Chari, V. V., \& Kehoe, P. J. (1990). Sustainable plans. Journal of political economy, 98(4), 783-802.

[16] Christiano, L. J., Trabandt T. and Walentin K. (2011). DSGE models for monetary policy analysis in Handbook of monetary economics, editors BM Friedman, M. Woodford, volume 3A.

[17] Clarida R., Gali J. and Gertler M. (1999). The Science of Monetary Policy: a new Keynesian Perspective. Journal of Economic Literature, 37(4), 1661-1707.

[18] Clarida R., Gali J. and Gertler M. (2000). Monetary Policy Rules and Macroeconomic Stability: Evidence and Some Theory. Quarterly Journal of Economics, 115(1), pp. 147-180.

[19] Cochrane J.H. (2011). Determinacy and Identification with Taylor Rules. Journal of Political Economy, 119(3), pp. 565-615.

[20] Cohen D. and Michel P. (1988). How Should Control Theory Be Used to Calculate a Time-Consistent Government Policy? Review of Economic Studies, 55, 119(3), 263-274.

[21] Debortoli, D., and Nunes, R. (2014). Monetary regime switches and central bank preferences. Journal of Money, Credit and Banking, 46(8), 1591-1626.

[22] Debortoli, D., \& Lakdawala, A. (2016). How credible is the Federal Reserve? A structural estimation of policy re-optimizations. American Economic Journal: Macroeconomics, 8(3), 42-76.

[23] Dees, S., Pesaran, M. H., Smith, L. V., \& Smith, R. P. (2009). Identification of new Keynesian Phillips curves from a global perspective. Journal of Money, Credit and Banking, 41(7), 1481-1502. 
[24] Duarte, P. G. (2009). A feasible and objective concept of optimal monetary policy: The quadratic loss function in the postwar period. History of Political Economy, 41(1), 1-55.

[25] Durbin, J. (1970). Testing for serial correlation in least-squares regressions when some of the regressors are lagged dependent variables. Econometrica 38: 410-421.

[26] Favero, C. A., \& Rovelli, R. (2003). Macroeconomic stability and the preferences of the Fed: A formal analysis, 1961-98. Journal of Money, Credit, and Banking, 35(4), 545-556.

[27] Fève P., Matheron J. and Poilly C. (2007). Monetary Policy Dynamics in the Euro Area. Economics Letters, 96(1), 97-102.

[28] Fujiwara, I., Kam, T., \& Sunakawa, T. (2016). A note on imperfect credibility. SSRN working paper.

[29] Gali J. (2015). Monetary Policy, Inflation, and the Business Cycle, (2nd edition) Princeton University Press.

[30] Giannoni, M., \& Woodford, M. (2004). Optimal inflation-targeting rules. In The Inflation-Targeting Debate (pp. 93-172). NBER, University of Chicago Press.

[31] Giordani and Söderlind (2004). Solution of Macromodels with Hansen-Sargent Robust Policies: some extensions. Journal of Economic Dynamics and Control, 12, $2367-2397$.

[32] Givens, G. E. (2012). Estimating central bank preferences under commitment and discretion. Journal of Money, credit and Banking, 44(6), 1033-1061.

[33] Griliches, Z. (1967). Distributed lags: a survey. Econometrica 35, 16-49.

[34] Hansen L.P. and Sargent T. (2008). Robustness, Princeton University Press, Princeton.

[35] Havranek, T., Rusnak, M., \& Sokolova, A. (2017). Habit formation in consumption: A meta-analysis. European Economic Review, 95, 142-167.

[36] Ilbas, P. (2012). Revealing the preferences of the US Federal Reserve. Journal of Applied Econometrics, 27(3), 440-473.

[37] Iskrev, N. (2010). Local identification in DSGE models. Journal of Monetary Economics, 57(2), 189-202.

[38] Juillard M., Karam P.D., Laxton D., Pesenti P.A. (2006). Welfare-based monetary policy rules in an estimated DSGE model of the US. ECB working paper 613.

[39] Kara, H. (2007). Monetary policy under imperfect commitment: Reconciling theory with evidence. International Journal of Central Banking. 3(1), 149-177.

[40] Kollmann R. (2002). Monetary policy rules in the open economy: effects on welfare and business cycles. Journal of Monetary Economics, 49(5), 989-1015. 
[41] Kollmann, R. (2008). Welfare-maximizing operational monetary and tax policy rules. Macroeconomic dynamics, 12(S1), 112-125.

[42] Komunjer, I., \& Ng, S. (2011). Dynamic identification of dynamic stochastic general equilibrium models. Econometrica, 79(6), 1995-2032.

[43] Kydland F. and Prescott E.C. (1980). Dynamic Optimal Taxation, Rational Expectations and Optimal Control. Journal of Economic Dynamics and Control, 2, pp.79-91.

[44] Leeper, E. M. (1991). Equilibria under 'active' and 'passive' monetary and fiscal policies. Journal of monetary Economics, 27(1), 129-147.

[45] Levieuge G., Lucotte Y. (2014). A Simple Empirical Measure of Central Banks' Conservatism, Southern Economic Journal, 81(2). 409-434.

[46] Ljungqvist L. and Sargent T.J. (2012). Recursive Macroeconomic Theory. 3rd edition. The MIT Press. Cambridge, Massaschussets.

[47] Matthes, C. (2015). Figuring Out the Fed-Beliefs about Policymakers and Gains from Transparency. Journal of Money, credit and Banking, 47(1), 1-29.

[48] Mavroeidis, S. (2005). Identification issues in forward-looking models estimated by GMM, with an application to the Phillips curve. Journal of Money, Credit, and Banking, 37(3), 421-448.

[49] Mavroeidis S. (2010). Monetary Policy Rules and Macroeconomic Stability: some new Evidence. American Economic Review. 100(1), pp. 491-503.

[50] Mavroeidis S., Plagbord-Moller M., Stock J.M. (2014). Empirical Evidence on Inflation Expectations in the New Keynesian Phillips Curve. Journal of Economic Literature. 52(1), pp.124-188.

[51] McManus, D.A., Nankervis, J.C., Savin, N.E. (1994). Multiple optima and asymptotic approximations in the partial adjustment model. Journal of Econometrics 62, 91-128.

[52] Oudiz G. and Sachs J. (1985). International Policy Coordination in Dynamic Macroeconomic Models, in W.H. Buiter and R.C. Marston (eds), International Economic Policy Coordination, Cambrdige, Cambridge University Press.

[53] Ozlale, U. (2003). Price stability vs. output stability: tales of federal reserve administrations, Journal of Economic Dynamics and Control, 27(9), 1595-1610.

[54] Paez-Farrell J. (2015). Taylor rules, central bank preferences and inflation targeting. Working Paper, university of Sheffield.

[55] Quah, D., \& Vahey, S. P. (1995). Measuring core inflation. The Economic Journal, $1130-1144$.

[56] Roberds, W. (1987). Models of policy under stochastic replanning. International Economic Review, 731-755. 
[57] Salemi, M. K. (1995). Revealed preference of the Federal Reserve: using inversecontrol theory to interpret the policy equation of a vector autoregression. Journal of Business \& Economic Statistics, 13(4), 419-433.

[58] Salemi, M. K. (2006). Econometric policy evaluation and inverse control. Journal of Money, Credit, and Banking, 38(7), 1737-1764.

[59] Salemi, M. K. (2010). It's what they do, not what they say. The New International Monetary System: Essays in Honour of Alexander Swoboda, chapter 11, p;162.

[60] Schaumburg, E., and Tambalotti, A. (2007). An investigation of the gains from commitment in monetary policy. Journal of Monetary Economics, 54(2), 302-324.

[61] Sims C.A. (1980). Macroeconomics and Reality. Econometrica, 48, 1-48.

[62] Simon H.A. (1956). Dynamic Programming under Uncertainty with a Quadratic Criterion Function. Econometrica, 24(1), 74-81.

[63] Söderlind P. (1999). Solution and estimation of RE macromodels with optimal policy. European Economic Review, 43(4), 813-823.

[64] Söderström, U., Söderlind, P., \& Vredin, A. (2005). New-Keynesian Models and Monetary Policy: A Re-examination of the Stylized Facts. The Scandinavian journal of economics, 107(3), 521-546.

\section{Appendix 1: Definition of data variables}

Mavroeidis data are running from 1960-Q1 to 2006-Q2.

Inflation is annualized quarter-on-quarter rate of inflation, $400 * \mathrm{LN}$ ( GDPDEF/ GDPDEF(-1)) with GDPDEF: Gross Domestic Product Implicit Price Deflator, 2000=100, Seasonally Adjusted. Released in August 2006. Source: U.S. Department of Commerce, Bureau of Economic Analysis.

GAPCBO is the output gap measure: $100 * \mathrm{LN}(\mathrm{GDPC} 1 / \mathrm{GDPPOT})$ with GDPC1: Real Gross Domestic Product, Billions of Chained 2000 Dollars, Seasonally Adjusted Annual Rate, Released in August 2006. Source: U.S. Department of Commerce, Bureau of Economic Analysis and GDPPOT: Real Potential Gross Domestic Product, Billions of Chained 2000 Dollars. Source: U.S. Congress, Congressional Budget Office.

Federal Funds Rate : Averages of Daily Figures - Percent, Source: Board of Governors of the Federal Reserve System

\subsection{Appendix 2: Augmented Discounted Linear Quadratic Reg- ulator}

The new-Keynesian Phillips curve can be written as a function of the Lagrange multiplier where $\kappa>0,0<\beta<1$ and $0<q<1$ (Debortoli and Nunes (2014, appendix A). We keep Gali (2015) chapter $5 \gamma_{t+1}$ notation of the Lagrange multiplier with one step ahead subscript: it corresponds to Debortoli and Nunes (2014) notation $\lambda_{t}$. Our notation for the stable eigenvalue $\lambda$ corresponds to Debortoli and Nunes (2014) notations " $\psi_{y}=1 / \gamma$ ".

$$
E_{t} \pi_{t+1}+\frac{\kappa^{2}}{\beta q \alpha_{x}} \gamma_{t+1}=\frac{1}{\beta q} \pi_{t}-\frac{1}{\beta q} u_{t}-\frac{1-q}{q} E_{t} \pi_{t+1}^{j}
$$


In what follows, $\beta$ refers to $\beta q$ to simplify notations. The solution of the Hamiltonian system are based on the demonstrations of the augmented discounted linear quadratic regulator in Anderson, Hansen, McGrattan and Sargent [1996], following the steps in Chatelain and Ralf (2017c):

$$
\left(\begin{array}{ccc}
1 & \frac{\kappa^{2}}{\beta \alpha_{x}} & 0 \\
0 & 1 & 0 \\
0 & 0 & 1
\end{array}\right)\left(\begin{array}{c}
\pi_{t+1} \\
\gamma_{t+1} \\
u_{t+1}
\end{array}\right)=\left(\begin{array}{ccc}
\frac{1}{\beta} & 0 & \frac{-1}{\beta} \\
-1 & 1 & 0 \\
0 & 0 & \rho
\end{array}\right)\left(\begin{array}{c}
\pi_{t} \\
\gamma_{t} \\
u_{t}
\end{array}\right)+\left(\begin{array}{c}
-\frac{1-q}{q} E_{t} \pi_{t+1}^{j} \\
0 \\
0
\end{array}\right)
$$

The Hamiltonian system is:

$$
\left(\begin{array}{c}
\pi_{t+1} \\
\gamma_{t+1} \\
u_{t+1}
\end{array}\right)=\left(\begin{array}{ccc}
\frac{1}{\beta}+\frac{\kappa^{2}}{\beta \alpha_{x}} & -\frac{\kappa^{2}}{\beta \alpha_{x}} & -\frac{1}{\beta} \\
-1 & 1 & 0 \\
0 & 0 & \rho
\end{array}\right)\left(\begin{array}{c}
\pi_{t} \\
\gamma_{t} \\
u_{t}
\end{array}\right)+\left(\begin{array}{c}
-\frac{1-q}{q} E_{t} \pi_{t+1}^{j} \\
0 \\
0
\end{array}\right)
$$

The characteristic polynomial of this upper square matrix is:

$$
\lambda^{2}-\left(1+\frac{1}{\beta}+\frac{\kappa^{2}}{\beta \alpha_{x}}\right) \lambda+\frac{1}{\beta}=0
$$

The Hamiltonian matrix has two stable roots $\rho$ and $\lambda$ ( $\lambda$ is denoted $\delta$ in Gali (2015)) and one unstable root $\frac{1}{\beta \lambda}$. The determinant of the matrix is $\rho \lambda \frac{1}{\beta \lambda}=\rho \frac{1}{\beta}$. Then $\lambda<\sqrt{\frac{1}{\beta}}<$ $\frac{1}{\beta \lambda}$. The trace of the matrix is

$$
\lambda=\frac{1}{2}\left(1+\frac{1}{\beta}+\frac{\kappa^{2}}{\beta \alpha_{x}}-\sqrt{\left(1+\frac{1}{\beta}+\frac{\kappa^{2}}{\beta \alpha_{x}}\right)^{2}-\frac{4}{\beta}}\right)
$$

Identification of $\frac{\kappa}{\alpha_{x}}$ : The characteristic polynomial is equal to zero. The policy rule parameter with respect to inflation depends on $\frac{\kappa}{\alpha_{x}}$ :

$$
\begin{aligned}
(1-\lambda)\left(1-\frac{1}{\beta \lambda}\right) & =-\frac{\kappa^{2}}{\beta \alpha_{x}} \Longrightarrow\left(\frac{1-\lambda}{\beta \lambda}\right)\left(\frac{\beta \lambda-1}{\kappa}\right)=-\frac{\kappa}{\beta \alpha_{x}} \Longrightarrow \\
F_{\pi} & =\frac{1-\beta \lambda}{\kappa}=\left(\frac{\lambda}{1-\lambda}\right) \frac{\kappa}{\alpha_{x}}
\end{aligned}
$$

Hamiltonian system function of the stable eigenvalue $\lambda$ (eliminating $\frac{\kappa}{\alpha_{x}}$ ):

$$
\left(\begin{array}{c}
\pi_{t+1} \\
\gamma_{t+1} \\
u_{t+1}
\end{array}\right)=\left(\begin{array}{ccc}
\lambda+\frac{1}{\beta \lambda}-1 & 1+\frac{1}{\beta}-\lambda-\frac{1}{\beta \lambda} & -\frac{1}{\beta} \\
-1 & 1 & 0 \\
0 & 0 & \rho
\end{array}\right)\left(\begin{array}{c}
\pi_{t+1} \\
\gamma_{t+1} \\
u_{t+1}
\end{array}\right)
$$

Proposition 1: Solution of Ricatti and Sylvester equation: Rule parameters $P_{u}$ and $P_{z}$ of the response of the Lagrange multiplier on inflation to exogenous variables: 


$$
\begin{aligned}
\gamma_{t} & =P_{\pi} \pi_{t}+P_{u} u_{t}+P_{z} z_{t} \\
P_{\pi} & =\frac{1}{1-\lambda}, P_{u}=\frac{1}{1-\lambda} \frac{\frac{1}{\beta}}{\rho-\frac{1}{\beta \lambda}}=\frac{1}{1-\lambda} \frac{\lambda}{\beta \lambda \rho-1} \text { and } P_{z}=\frac{1}{1-\lambda} \frac{\frac{1}{\beta}}{\mu-\frac{1}{\beta \lambda}}=\frac{1}{1-\lambda} \frac{\lambda}{\beta \lambda \mu-1}
\end{aligned}
$$

Demonstration: It uses the method of undetermined coefficients of Anderson, Hansen, McGrattan and Sargent's (1996), section 5. The solution is the one that stabilizes the state-costate vector for any initialization of inflation $\pi_{0}$ and of the exogenous variables $u_{0}$ in a stable subspace of dimension two within a space of dimension three $\left(\pi_{t}, \gamma_{t}, u_{t}\right)$ of the Hamiltonian system. We seek a characterization of the Lagrange multiplier $\gamma_{t}$ of the form:

$$
\gamma_{t}=P_{\pi} \pi_{t}+P_{u} u_{t}+P_{z} z_{t}
$$

To deduce the control law associated with vector $\left(P_{\pi}, P_{u}, P_{z}\right)$, we substitute it into the Hamiltonian system:

$$
\begin{aligned}
& \left(\begin{array}{c}
\pi_{t+1} \\
P_{\pi} \pi_{t+1}+P_{u} u_{t+1}+P_{z} z_{t+1} \\
u_{t+1}
\end{array}\right) \\
& =\left(\begin{array}{ccc}
\frac{1}{\beta}-(1-\lambda)\left(1-\frac{1}{\beta \lambda}\right) & (1-\lambda)\left(1-\frac{1}{\beta \lambda}\right) & -\frac{1}{\beta} \\
-1 & 1 & 0 \\
0 & 0 & \rho
\end{array}\right)\left(\begin{array}{c}
\pi_{t} \\
P_{\pi} \pi_{t}+P_{u} u_{t}+P_{z} z_{t} \\
u_{t}
\end{array}\right)
\end{aligned}
$$

We write the last two equations in this system separately:

$$
\begin{aligned}
P_{\pi} \pi_{t+1}+P_{u} u_{t+1}+P_{z} z_{t+1} & =\left(P_{\pi}-1\right) \pi_{t}+P_{u} u_{t}+P_{z} z_{t} \\
u_{t+1} & =\rho u_{t}
\end{aligned}
$$

It follows that:

$$
\pi_{t+1}=\frac{P_{\pi}-1}{P_{\pi}} \pi_{t}+\frac{(1-\rho) P_{u}}{P_{\pi}} u_{t}+\frac{(1-\mu) P_{z}}{P_{\pi}} z_{t}
$$

The first equation is such that:

$$
\pi_{t+1}=\left[\frac{1}{\beta}-(1-\lambda)\left(1-\frac{1}{\beta \lambda}\right)\right] \pi_{t}+(1-\lambda)\left(1-\frac{1}{\beta \lambda}\right)\left(P_{\pi} \pi_{t}+P_{u} u_{t}+P_{z} z_{t}\right)-\frac{1}{\beta} u_{t}-\frac{1}{\beta} z_{t}
$$

Factorizing: 


$$
\begin{aligned}
\pi_{t+1} & =\left[\frac{1}{\beta}-(1-\lambda)\left(1-\frac{1}{\beta \lambda}\right)+(1-\lambda)\left(1-\frac{1}{\beta \lambda}\right) P_{\pi}\right] \pi_{t}+\left[(1-\lambda)\left(1-\frac{1}{\beta \lambda}\right) P_{u}-\frac{1}{\beta}\right] u_{t} \\
& +\left[(1-\lambda)\left(1-\frac{1}{\beta \lambda}\right) P_{z}-\frac{1}{\beta}\right] z_{t}
\end{aligned}
$$

The method of undetermined coefficients implies for the first term:

$$
\begin{aligned}
\frac{P_{\pi}-1}{P_{\pi}} & =\frac{1}{\beta}+(1-\lambda)\left(1-\frac{1}{\beta \lambda}\right)\left(P_{\pi}-1\right) \\
P_{\pi} & =\frac{1}{1-\lambda}
\end{aligned}
$$

For the second term:

$$
\begin{aligned}
\frac{(1-\rho) P_{u}}{P_{\pi}} & =(1-\lambda)\left(1-\frac{1}{\beta \lambda}\right) P_{u}-\frac{1}{\beta} \Rightarrow \\
\frac{1}{\beta} & =\left(1-\frac{1}{\beta \lambda}-1+\rho\right)(1-\lambda) P_{u} \Rightarrow \\
P_{u} & =\frac{1}{1-\lambda} \frac{\frac{1}{\beta}}{\rho-\frac{1}{\beta \lambda}} \Rightarrow \frac{P_{u}}{P_{\pi}}=\frac{\frac{1}{\beta}}{\rho-\frac{1}{\beta \lambda}}=\frac{-\lambda}{1-\lambda \beta \rho}
\end{aligned}
$$

For the third term:

$$
\frac{(1-\mu) P_{z}}{P_{\pi}}=(1-\lambda)\left(1-\frac{1}{\beta \lambda}\right) P_{z}-\frac{1}{\beta} \Rightarrow P_{z}=\frac{\frac{1}{\beta}}{(1-\lambda)\left(\mu-\frac{1}{\beta \lambda}\right)}
$$

QED

Proposition 2: Optimal policy rule parameters formulas:

$$
\begin{aligned}
& F_{\pi}=\frac{\kappa}{\alpha_{x}}\left(P_{\pi}-1\right)=\lambda \frac{\kappa}{\alpha_{x}} P_{\pi}=\frac{\kappa}{\alpha_{x}} \frac{\lambda}{1-\lambda}=\frac{1-\beta \lambda}{\kappa} \\
& F_{u}=\frac{\kappa}{\alpha_{x}} P_{u}=\frac{\kappa}{\alpha_{x}} P_{\pi} \frac{\lambda}{\beta \lambda \rho-1}=\frac{\kappa}{\alpha_{x}} \frac{1}{1-\lambda} \frac{\lambda}{\beta \lambda \rho-1} \\
& F_{z}=\frac{\kappa}{\alpha_{x}} P_{z}=\frac{\kappa}{\alpha_{x}} P_{\pi} \frac{\lambda}{\beta \lambda \mu-1}=\frac{\kappa}{\alpha_{x}} \frac{\lambda}{1-\lambda} \frac{1}{\beta \lambda \mu-1} \\
& \frac{F_{u}}{F_{\pi}}=A=\frac{1}{\lambda} \frac{P_{u}}{P_{\pi}}=\frac{1}{\beta \lambda \rho-1}=\frac{P_{u}}{P_{\pi}-1}=-1+\beta \rho \frac{P_{u}}{P_{\pi}} \\
& \frac{F_{z}}{F_{\pi}}=B=\frac{1}{\lambda} \frac{P_{z}}{P_{\pi}}=\frac{1}{\beta \lambda \mu-1}
\end{aligned}
$$

\section{Demonstration:}

The first order condition relates Lagrange multiplier to the policy instrument: 


$$
\begin{aligned}
x_{t} & =\frac{\kappa}{\alpha_{x}} \gamma_{t+1}=\frac{\kappa}{\alpha_{x}}\left(\gamma_{t}-\pi_{t}\right) \\
x_{t} & =F_{\pi} \pi_{t}+F_{u} u_{t}+F_{z} z_{t}=\frac{\kappa}{\alpha_{x}}\left(\gamma_{t}-\pi_{t}\right)=\frac{\kappa}{\alpha_{x}}\left(P_{\pi} \pi_{t}+P_{u} u_{t}+P_{z} z_{t}-\pi_{t}\right) \Rightarrow \\
F_{\pi} & =\frac{\kappa}{\alpha_{x}}\left(P_{\pi}-1\right), F_{u}=\frac{\kappa}{\alpha_{x}} P_{u} \text { and } F_{z}=\frac{\kappa}{\alpha_{x}} P_{z}
\end{aligned}
$$

Proposition 3: From LQR to Gali (2015) vector basis (replace policy target by policy instrument).

One has:

$$
\frac{-1-\kappa F_{u}}{\beta}=\frac{-1-\kappa A \frac{1-\beta \lambda}{\kappa}}{\beta}=\frac{1}{\beta \lambda \rho-1} \lambda-\frac{1}{\beta}-\frac{\frac{1}{\beta \lambda \rho-1}}{\beta}=\frac{(1-\rho) \lambda}{\beta \lambda \rho-1}=(1-\rho) \lambda A
$$

One has:

$$
\begin{gathered}
\left\{\begin{array}{c}
\left(\begin{array}{c}
u_{t+1} \\
\pi_{t+1}
\end{array}\right)=\left(\begin{array}{cc}
\rho & 0 \\
(1-\rho) A \lambda & \lambda
\end{array}\right)\left(\begin{array}{c}
u_{t} \\
\pi_{t}
\end{array}\right)+\left(\begin{array}{c}
\varepsilon_{t} \\
0
\end{array}\right) \\
\left(\begin{array}{c}
u_{t} \\
x_{t}
\end{array}\right)=\left(\begin{array}{cc}
1 & 0 \\
A F_{\pi} & F_{\pi}
\end{array}\right)\left(\begin{array}{l}
u_{t} \\
\pi_{t}
\end{array}\right)=\mathbf{N}\left(\begin{array}{c}
u_{t} \\
\pi_{t}
\end{array}\right) \\
x_{t}=F_{\pi} \pi_{t}+A F_{\pi} u_{t}
\end{array}\right. \\
\Leftrightarrow\left\{\begin{array}{c}
\left(\begin{array}{c}
u_{t+1} \\
x_{t+1}
\end{array}\right)=\mathbf{N}^{-1}(\mathbf{A}+\mathbf{B F}) \mathbf{N}\left(\begin{array}{c}
u_{t} \\
x_{t}
\end{array}\right)+\mathbf{N}^{-1}\left(\begin{array}{c}
\varepsilon_{t} \\
0
\end{array}\right) \\
\left(\begin{array}{c}
u_{t} \\
\pi_{t}
\end{array}\right)=\mathbf{N}^{-1}\left(\begin{array}{c}
u_{t} \\
x_{t}
\end{array}\right) \\
\pi_{t}=\frac{1}{F_{\pi}} x_{t}-A \pi_{t}
\end{array}\right.
\end{gathered}
$$

One has:

$$
\mathbf{N}^{-1}(\mathbf{A}+\mathbf{B F}) \mathbf{N}=\left(\begin{array}{cc}
\rho & 0 \\
(1-\lambda) F_{\pi} A \rho & \lambda
\end{array}\right)
$$

Which is Gali (2015) representation of the solution:

$$
x_{t}=\lambda x_{t-1}+(1-\lambda) F_{\pi} A \rho u_{t-1}=\lambda x_{t-1}+\frac{\kappa}{\alpha_{x}} \frac{\lambda}{\beta \lambda \rho-1} \rho u_{t-1}
$$

QED

Because the auto-correlation $\lambda$ of the policy instrument $x_{t}$ and the auto-correlation of the cost-push shock are competing to explain the persistence of the policy instrument $x_{t}$, this partial adjustment model with serially correlated shocks has a problem of identification and multiple equilibria (Griliches (1967), Blinder (1986), McManus et al. (1994), Fève, Matheron Poilly (2007)). Hence, we compute the representation of Ramsey optimal policy as a bivariate VAR of two observable variables (inflation and the policy instrument).

Proposition 4: From LQR to a bivariate VAR with observable variables: 


$$
\begin{aligned}
& \left\{\begin{array}{c}
\left(\begin{array}{l}
\pi_{t+1} \\
u_{t+1}
\end{array}\right)=\left(\begin{array}{cc}
\lambda & (1-\rho) A \lambda \\
0 & \rho
\end{array}\right)\left(\begin{array}{l}
\pi_{t} \\
u_{t}
\end{array}\right)+\left(\begin{array}{c}
0 \\
\varepsilon_{t}
\end{array}\right) \\
\left(\begin{array}{l}
\pi_{t} \\
x_{t}
\end{array}\right)=\left(\begin{array}{cc}
1 & 0 \\
F_{\pi} & A F_{\pi}
\end{array}\right)^{-1}\left(\begin{array}{l}
\pi_{t} \\
u_{t}
\end{array}\right)=\mathbf{M}\left(\begin{array}{c}
u_{t} \\
\pi_{t}
\end{array}\right) \\
i_{t}=F_{\pi} \pi_{t}+A F_{\pi} u_{t}
\end{array}\right. \\
& \Leftrightarrow\left\{\begin{array}{c}
\left(\begin{array}{c}
\pi_{t+1} \\
x_{t+1}
\end{array}\right)=\mathbf{M}^{-1}(\mathbf{A}+\mathbf{B F}) \mathbf{M}\left(\begin{array}{c}
\pi_{t} \\
x_{t}
\end{array}\right)+\mathbf{M}^{-1}\left(\begin{array}{c}
0 \\
\varepsilon_{t}
\end{array}\right) \\
\left(\begin{array}{c}
\pi_{t} \\
u_{t}
\end{array}\right)=\left(\begin{array}{cc}
1 & 0 \\
-\frac{1}{A} & \frac{1}{A F_{\pi}}
\end{array}\right)\left(\begin{array}{c}
\pi_{t} \\
x_{t}
\end{array}\right)=\mathbf{M}^{-1}\left(\begin{array}{c}
\pi_{t} \\
x_{t}
\end{array}\right) \\
u_{t}=-\frac{1}{A} \pi_{t}+\frac{1}{A F_{\pi}} x_{t}
\end{array}\right.
\end{aligned}
$$

Then:

$$
\begin{aligned}
& \left(\begin{array}{cc}
1 & 0 \\
F_{\pi} & A F_{\pi}
\end{array}\right)\left(\begin{array}{cc}
\lambda & (1-\rho) A \lambda \\
0 & \rho
\end{array}\right)\left(\begin{array}{cc}
1 & 0 \\
F_{\pi} & A F_{\pi}
\end{array}\right)^{-1} \\
& =\left(\begin{array}{cc}
\lambda \rho & (1-\rho) \lambda \frac{1}{F_{\pi}} \\
\rho(\lambda-1) F_{\pi} & \lambda+\rho-\lambda \rho
\end{array}\right)=\left(\begin{array}{cc}
\lambda \rho & (1-\rho)(1-\lambda) \frac{\alpha_{x}}{\kappa} \\
-\rho \lambda \frac{\kappa}{\alpha_{x}} & \lambda+\rho-\lambda \rho
\end{array}\right)
\end{aligned}
$$

QED.

\section{NOT FOR PUBLICATION}

\subsection{Appendix 3: Identification issue for reduced form including a non-observable $\operatorname{AR}(1)$ shock.}

Because the auto-correlation of the policy instrument $x_{t}$ and the auto-correlation of the cost-push shock are competing to explain the persistence of the policy instrument $x_{t}$, this partial adjustment model with serially correlated shocks has a problem of identification and multiple equilibria (Griliches (1967), Blinder (1986), McManus et al. (1994), Fève, Matheron Poilly (2007)). This VAR(1) can be written as:

$$
x_{t}=\lambda_{R} x_{t-1}+\eta_{t} \text { and } \eta_{t}=\rho \eta_{t-1}+\varepsilon_{\eta, t}
$$

where $\eta_{t}=-\frac{\kappa}{\alpha_{x}} \frac{\lambda_{R}}{\left(1-\lambda_{R} \rho \beta\right)} u_{t}$. It is an $\operatorname{AR}(2)$ model of the policy instrument rule:

$$
\begin{aligned}
& x_{t}=\lambda_{R} x_{t-1}+\rho\left(x_{t-1}-\lambda_{R} x_{t-2}\right)+\varepsilon_{\eta, t} \\
& x_{t}=b_{1} x_{t-1}+b_{2} x_{t-2}+\varepsilon_{\eta, t} \text { with } b_{1}=\lambda_{R}+\rho \text { and } b_{2}=-\lambda_{R} \rho .
\end{aligned}
$$

The structural parameter $\rho$ and the semi-structural parameter $\lambda_{R}$ are functions of reduced form parameters $b_{1}$ and $b_{2}$ solutions of:

$$
X^{2}-b_{1} X-b_{2}=0
$$

which are given by: 


$$
\lambda_{R}=\frac{b_{1} \pm \sqrt{b_{1}^{2}+4 b_{2}}}{2} \text { and } \rho=\beta b-\lambda_{R}
$$

where $\Delta=b_{1}^{2}+4 b_{2}=\left(\rho-\lambda_{R}\right)^{2}$. If $\Delta \neq 0$ and $\rho \neq \lambda_{R}$, two sets of values for $\lambda_{R}$ and $\rho$ are observationally equivalent. The first solution is such that $\lambda_{R}>\rho$ and the second solution is such that $\lambda_{R}<\rho$. The larger $\Delta$, the larger the identification issue, because it increases the gap between a more inertial monetary policy with lower correlation of monetary policy shocks and a less inertial monetary policy, that we cannot distinguish. The ADLQR representation and Gali (2015) representation of the stationary solution of the VAR(1) of optimal policy are not useful to identify parameters, because they include the cost-push shock $u_{t}$ which is not observable.

The reduced form estimated variance $\sigma_{\eta}$ provides another equation with a theoretical positive sign restriction $\frac{\kappa}{\alpha_{x}} \frac{\lambda_{R}}{\left(1-\lambda_{R} \rho \beta\right)}>0$ for five unknowns structural parameters $\left(\alpha_{x}, \kappa, \rho, \beta, \sigma_{u}\right)$ :

$$
\frac{\kappa}{\alpha_{x}} \frac{\lambda_{R}}{\left(1-\lambda_{R} \rho \beta\right)} \sigma_{u}=\sigma_{\eta}
$$

\subsection{Appendix 4: Oudiz and Sachs (1985) versus Gali (2015) time consistent policy}

Substituting the private sector's inflation rule (8) and policy rule (9) in the inflation law of motion (1) and comparing it with the forcing variable law of motion (2) leads to the following relation between $N_{Z C}$ on date $t, N_{Z C, t+1}$ and $F_{u, Z C}$ :

$$
\begin{aligned}
\pi_{t} & =\beta E_{t}\left[\pi_{t+1}\right]+\kappa x_{t}+u_{t} \Rightarrow \\
N_{Z C} u_{t} & =\beta N_{Z C, t+1} \rho u_{t}+\kappa F_{u, Z C} u_{t}+u_{t} \\
N_{Z C} & =\beta \rho N_{Z C, t+1}+\kappa F_{u, Z C}+1
\end{aligned}
$$

A myopic central bank does not notice that $N_{Z C, t+1}=N_{Z C}$ (Gali (2015)) in its optimization:

$$
\begin{aligned}
N_{Z C, \text { Gali }} & =\beta \rho N_{Z C, t+1}+\kappa F_{u, Z C}+1 \Rightarrow \frac{\partial N_{Z C, \text { Gali }}}{\partial F_{u, Z C}}=\kappa \\
F_{\pi, Z C} & =\frac{F_{u, Z C}}{N_{Z C}}=-\frac{\kappa}{\alpha_{x}}<0
\end{aligned}
$$

This first order condition of the central bank optimization is substituted into the newKeynesian Phillips curve equation, where, only at this stage, players of the game discover that it is assumed $N_{Z C, t+1}=N_{Z C, t}=N_{Z C}$. Gali's (2015) solutions are:

$$
\begin{aligned}
F_{u, Z C, \text { Gali }} & =-\frac{\kappa}{\kappa^{2}+\alpha_{x}(1-\beta \rho)}=-\frac{\kappa}{\alpha_{x}} N_{Z C} \\
N_{Z C, \text { Gali }} & =\frac{\alpha_{x}}{\kappa^{2}+\alpha_{x}(1-\beta \rho)} \rightarrow \frac{1}{1-\beta \rho}=N \text { when } \alpha_{x} \rightarrow+\infty
\end{aligned}
$$


In zero-credibility equilibrium (Oudiz and Sachs (1985)), the central bank does foresees that $N_{Z C, t+1}=N_{Z C}$ in its optimization, with the following solutions, that we consider for the remaining part of the paper:

$$
\begin{aligned}
N_{Z C} & =\frac{\kappa F_{u, Z C}+1}{1-\beta \rho}=\frac{\kappa F_{\pi, Z C} N_{Z C}+1}{1-\beta \rho} \Rightarrow \frac{\partial N_{u, Z C}}{\partial F_{u, Z C}}=\frac{\kappa}{1-\beta \rho} \\
F_{\pi, Z C} & =\frac{F_{u, Z C}}{N_{Z C}}=-\frac{\kappa}{\alpha_{x}} \frac{1}{1-\beta \rho}=-\frac{\kappa}{\alpha_{x}}<0 \\
F_{u, Z C} & =-\frac{\kappa}{\kappa^{2}+\alpha_{x}(1-\beta \rho)^{2}} \\
N_{Z C} & =\frac{\alpha_{x}(1-\beta \rho)}{\kappa^{2}+\alpha_{x}(1-\beta \rho)^{2}} \rightarrow \frac{1}{1-\beta \rho}=N \text { when } \alpha_{x} \rightarrow+\infty
\end{aligned}
$$

In Oudiz and Sachs' (1985) general solution, this is the condition after substitutions of the private sector's rule (matrix $N_{Z C}$ ) and the policy maker's rule (matrix $F_{u, Z C}$ ) for both dates $t$ and $t+1$ into the law of motion of the private sector dynamics:

$$
\begin{aligned}
N_{Z C, t} & =J-K F_{u, Z C} \\
J & =\left(A_{22}+N_{Z C, t+1} A_{12}\right)^{-1}\left(N_{Z C, t+1} A_{11}+A_{21}\right) \\
K & =\left(A_{22}+N_{Z C, t+1} A_{12}\right)^{-1}\left(N_{Z C, t+1} B_{1}+B_{2}\right)
\end{aligned}
$$

with general notations and equalities with Gali's (2015) transmission mechanism:

$$
\left(\begin{array}{c}
u_{t+1} \\
\pi_{t+1}
\end{array}\right)=\left(\begin{array}{cc}
A_{11}=\rho & A_{12}=0 \\
A_{21}=-\frac{1}{\beta} & A_{22}=\frac{1}{\beta}
\end{array}\right)\left(\begin{array}{c}
u_{t} \\
\pi_{t}
\end{array}\right)+\left(\begin{array}{c}
B_{1}=0 \\
B_{2}=-\frac{\kappa}{\beta}
\end{array}\right) x_{t}
$$

In Oudiz and Sachs (1985), $N_{Z C, t+1}=N_{Z C, t}$ at all dates, whereas Gali (2015) assumes myopia (or $N_{Z C, t+1}=0$ ) for the policy maker. This assumption changes the initial jump of inflation, impulse response functions of inflation and the output gap and welfare. It does not change the identification problem of discretion raised in this paper, because the stable subspace of discretion have the same dimension (one) using the reference Oudiz and Sachs (1985) discretion equilibrium or Gali (2015) and Clarida, Gali, Gertler (1999) myopia assumption.

\subsection{Appendix 5: Code for 3 estimations of Ramsey optimal policy}

The first estimation estimates the two stable eigenvalues: the exogenous $\rho$, the reduced form $\lambda$ and the reduced from policy rule parameter with respect to inflation $F_{\pi}$.

by id1: nlsur (inflation $\left.=\left(\{\mathrm{r}\}^{*}\{\mathrm{l}\}\right) * \operatorname{linflation}+\left(\{1\}^{*}(1-\{\mathrm{r}\}) /\{\mathrm{F}=1\}\right) * \mathrm{lfyff}+\{\mathrm{b} 3\}\right) / / /$

$($ fyff $=(\{\mathrm{r}\} *(\{\mathrm{l}\}-1) *\{\mathrm{~F}\}) * \operatorname{linflation}+(\{\mathrm{r}\}+\{\mathrm{l}\}-\{\mathrm{r}\} *\{\mathrm{l}\}) * \operatorname{lfyff}+\{\mathrm{b} 6\}) / / /$

if $\mathrm{tt}>1$

The second estimation estimates the two stable eigenvalues: the exogenous $\rho$, the reduced form $\lambda$ and the ratio of two structural parameters $\frac{\alpha_{x}}{\kappa}$ (the Fed's preference divided by the slope of the new-Keynesian Phillips curve). This estimate of $\frac{\alpha_{x}}{\kappa}$ is an estimate of $\frac{1}{\varepsilon}$, the household's elasticity of substitution between each differentiated goods $\varepsilon$, if the 
Fed's preferences corresponds to consumers' welfare.

by id1: nlsur (inflation $=\{\mathrm{r}=1\} *\{\mathrm{l}=0.5\}^{*}$ linflation $/ / /$

$+(1-\{\mathrm{r}\}) *(1-\{1\}) *\{\mathrm{G}=1\} *$ lfyff $+\{\mathrm{b} 3\}) / / /$

(fyff $=-\{\mathrm{r}\}^{*}\{\mathrm{l}\} /\{\mathrm{G}=1\}^{*}$ linflation $/ / / /$

$+(\{\mathrm{r}\}+(1-\{\mathrm{r}\}) *\{1\}) * \operatorname{lfyff}+\{\mathrm{b} 6\}) / / /$

if $t \mathrm{t}>1$

The third estimation requires an identification restriction that we set on the discount factor $\beta$ ( $\beta=1$ or $\beta=0.99)$. We estimate separately three structural parameters: the auto-correlation of the cost-push shock $\rho$, the preference of the Fed $\alpha_{x}$, and the slope of the new-Keynesian Phillips curve $\kappa$.

by id1: nlsur (inflation $=\{\mathrm{r}=1\}^{*}\left(1+0.5^{*}\left(\{\mathrm{k}\}^{\wedge} 2 /\{\mathrm{a}=1\}\right)-\operatorname{sqrt}\left(-1+\left(1+0.5^{*}\left(\{\mathrm{k}\}^{\wedge} 2 /\{\mathrm{a}\}\right)\right)^{\wedge} 2\right)\right.$ )*linflation /// // $/$

$$
\left.+(1-\{\mathrm{r}\})^{*}\left(1-\left(1+0.5^{*}\left(\{\mathrm{k}\}^{\wedge} 2 /\{\mathrm{a}\}\right)-\operatorname{sqrt}\left(-1+\left(1+0.5^{*}\left(\{\mathrm{k}\}^{\wedge} 2 /\{\mathrm{a}\}\right)\right)^{\wedge} 2\right)\right)\right)^{*}\{\mathrm{a}\} /\{\mathrm{k}=1\}^{*} \mathrm{lfyff}+\{\mathrm{b} 3\}\right)
$$

$\left(\right.$ fyff $=-\{\mathrm{r}\}^{*}\left(1+0.5^{*}\left(\{\mathrm{k}\}^{\wedge} 2 /\{\mathrm{a}\}\right)-\operatorname{sqrt}\left(-1+\left(1+0.5^{*}\left(\{\mathrm{k}\}^{\wedge} 2 /\{\mathrm{a}\}\right)\right)^{\wedge} 2\right)\right)^{*}\{\mathrm{k}\} /\{\mathrm{a}\}^{*}$ linflation $/ / /$

$\left.+\left(\{\mathrm{r}\}+(1-\{\mathrm{r}\})^{*}\left(1+0.5^{*}\left(\{\mathrm{k}\}^{\wedge} 2 /\{\mathrm{a}\}\right)-\operatorname{sqrt}\left(-1+\left(1+0.5^{*}\left(\{\mathrm{k}\}^{\wedge} 2 /\{\mathrm{a}\}\right)\right)^{\wedge} 2\right)\right)\right)^{*} \mathrm{lfyff}+\{\mathrm{b} 6\}\right)$ $/ / /$

if $\mathrm{tt}>1$

by id1: nlsur (inflation $=\{\mathrm{r}=1\}^{*}\left(1.005051+0.505051^{*}\left(\{\mathrm{k}\}^{\wedge} 2 /\{\mathrm{a}=1\}\right)-\operatorname{sqrt}(-1.010101+(1.005051+0.5\right.$ *linflation ///

$+(1-\{\mathrm{r}\})^{*}\left(1-\left(1.005051+0.505051^{*}\left(\{\mathrm{k}\}^{\wedge} 2 /\{\mathrm{a}=1\}\right)-\operatorname{sqrt}\left(-1.010101+\left(1.005051+0.505051^{*}\left(\{\mathrm{k}\}^{\wedge} 2 /\{\mathrm{a}\}\right.\right.\right.\right.\right.$ )$*\{a\} /\{\mathrm{k}=1\} *$ lfyff $+\{\mathrm{b} 3\}) / / /$

$\left(\right.$ fyff $=-\{\mathrm{r}\}^{*}\left(1.005051+0.505051^{*}\left(\{\mathrm{k}\}^{\wedge} 2 /\{\mathrm{a}=1\}\right)-\operatorname{sqrt}\left(-1.010101+\left(1.005051+0.505051^{*}\left(\{\mathrm{k}\}^{\wedge} 2 /\{\mathrm{a}\}\right)\right)\right.\right.$ )$^{*}\{\mathrm{k}\} /\{\mathrm{a}\} *$ linflation $/ / /$

$+\left(\{\mathrm{r}\}+(1-\{\mathrm{r}\})^{*}\left(1.005051+0.505051^{*}\left(\{\mathrm{k}\}^{\wedge} 2 /\{\mathrm{a}=1\}\right)-\operatorname{sqrt}\left(-1.010101+\left(1.005051+0.505051^{*}\left(\{\mathrm{k}\}^{\wedge} 2 /\{\right.\right.\right.\right.\right.$ )$* \operatorname{lfyff}+\{\mathrm{b} 6\}) / / /$

if $t t>1$ 